\title{
CAMA
}

Centre for Applied Macroeconomic Analysis

\section{Absolute Momentum, Sustainable Withdrawal Rates and Glidepath Investing in US Retirement Portfolios from 1925}

\section{CAMA Working Paper 31/2019 Aprill 2019}

Andrew Clare

Cass Business School, City University London

James Seaton

Cass Business School, City University London

Peter N. Smith

University of York

Centre for Applied Macroeconomic Analysis, ANU

\section{Stephen Thomas}

Cass Business School, City University London

\section{Abstract}

A significant part of the development in pension provision in many countries is the emergence of 'Target Date Funds' or TDFs. In this paper we examine the proposition of de-risking through life and the guidance offered by TDFs in the decumulation phase following retirement. We investigate the withdrawal experience associated with Glidepath Investing in the US since 1925 for conventional bond-equity portfolios. We find one very powerful conclusion: that smoothing the returns on individual assets by simple absolute momentum or trend following techniques is a potent tool to enhance withdrawal rates, often by as much as 50\% per annum! And, perhaps of even greater social relevance is that it removes the 'left-tail' of unfortunate withdrawal rate experiences, i.e. the bad luck of a poor sequence of returns early in decumulation. We show that diversifying assets over time by switching between an asset and cash in a systematic way is potentially more important for the retirement income experience than diversifying one's portfolio across asset classes. We also show that Glidepath investing is only sensible within a few years of the target date. This finding provides succour to enthusiasts for target date investing in the face of the growing hostility in the literature. 


\section{Keywords}

Sequence Risk, Perfect Withdrawal Rate, Decumulation, Absolute Momentum, Trend Following

\section{JEL Classification}

G10, G11, G22

\section{Address for correspondence:}

(E) cama.admin@anu.edu.au

\section{ISSN 2206-0332}

The Centre for Applied Macroeconomic Analysis in the Crawford School of Public Policy has been established to build strong links between professional macroeconomists. It provides a forum for quality macroeconomic research and discussion of policy issues between academia, government and the private sector.

The Crawford School of Public Policy is the Australian National University's public policy school, serving and influencing Australia, Asia and the Pacific through advanced policy research, graduate and executive education, and policy impact. 


\title{
Absolute Momentum, Sustainable Withdrawal Rates and Glidepath Investing in US Retirement Portfolios from 1925
}

\author{
By \\ Andrew Clare*, \\ James Seaton*, \\ Peter N. Smith $\uparrow$ \\ and \\ Stephen Thomas* \\ *Cass Business School, City University London \\ $\dagger$ University of York and Centre for Applied Macroeconomic Analysis (CAMA).
}

This Version: $4^{\text {th }}$ March 2019

\begin{abstract}
A significant part of the development in pension provision in many countries is the emergence of 'Target Date Funds' or TDFs. In this paper we examine the proposition of de-risking through life and the guidance offered by TDFs in the decumulation phase following retirement. We investigate the withdrawal experience associated with Glidepath Investing in the US since 1925 for conventional bond-equity portfolios. We find one very powerful conclusion: that smoothing the returns on individual assets by simple absolute momentum or trend following techniques is a potent tool to enhance withdrawal rates, often by as much as $50 \%$ per annum! And, perhaps of even greater social relevance is that it removes the 'left-tail' of unfortunate withdrawal rate experiences, i.e. the bad luck of a poor sequence of returns early in decumulation. We show that diversifying assets over time by switching between an asset and cash in a systematic way is potentially more important for the retirement income experience than diversifying one's portfolio across asset classes. We also show that Glidepath investing is only sensible within a few years of the target date. This finding provides succour to enthusiasts for target date investing in the face of the growing hostility in the literature
\end{abstract}

Keywords: Sequence Risk; Perfect Withdrawal Rate; Decumulation; Absolute Momentum; Trend Following.

JEL Classification: G10, G11, G22. 
"Buy-and-hold doesn't work anymore. The volatility is too significant. Almost any asset can suddenly become much more risky."

Andrew Lo (2012).

"We have got a model for cross-section diversification. We have to balance that with time-series diversification because when time diversification fails, cross-section diversification fails too .... The greatest reward comes from time diversification."

Myron Scholes,

in Cao, Larry, (2016), Managing Multi-Asset Strategies, CFA Institute.

\section{Introduction}

A significant part of the development in pension provision in many countries is the emergence of 'Target Date Funds' or TDFs. Previously ubiquitous 'Defined Benefits' DB pensions schemes are fast being replaced by 'Defined Contributions' DC schemes. These schemes move most of the risks associated with pension provision to the individual and away from the scheme sponsor. DC schemes generate an investment fund for the individual which must be managed throughout their working and retirement years. TDFs have emerged as the means by which many individuals change the composition of their portfolio of assets over their remaining lifetime. TDFs are typically structured around a 'glidepath' under which the individual fund is predominantly invested in higher return, higher risk equities whilst the individual is young reducing that proportion through later life in favour of ostensibly lower risk, primarily government bonds. The economic motivation for this is the better ability of younger investors to withstand equity risk due to the large proportion of their total wealth which is in the form of low-risk human capital. This argument for this lifecycle pattern of equity holding was originally made by Merton (1971) developing the original Samuelson (1969) and Merton (1969) models which suggested that consumer/investors hold a constant share of the risky asset throughout their lifetime. The approach of Merton is developed in a more realistic form allowing for the uncertain nature of labour income and costs of participation in equity markets by Cocco et al (2005). In this paper we examine the proposition of de-risking through life and the guidance offered by TDFs in the decumulation phase following retirement. Issues of optimal portfolio choice in the working phase are complicated by the periodic contributions, mostly through labour income, made to retirement funds and are not addressed here.

An example of a widely held TDF is that offered by Vanguard group and presented in detail in Donaldson et al (2015). This shows a 50\% investment of funds for retirement in equities upon retirement, reducing to $30 \%$ after a further 7 years. Both of these figures are significantly lower than the $90 \%$ investment in equities proposed for the first 15 years of working life followed by a glide down over the remaining 25 working years. In their case, Vanguard are following "the theoretical concept that equity allocations should decline with age to help manage risk through time", Donaldson et al $(2015, \mathrm{p} 4)$, as per the theoretical models.

There is, however, a significant literature arguing the opposite case to Vanguard and the literature above, namely that investment should move from less to more aggressive over the lifecycle. After all, as Shiller (2005) observed, under some alternative assumptions, it is optimal 
for young people to invest little in equities and to increase that proportion over their lifetime. Blanchett (2007) compares fixed asset allocations to a wide range of investment paths that reduce the allocation to equity during retirement. He finds that fixed asset allocations provide superior results compared to asset allocations which tend to reduce equity investments in retirement. Arnott, Sherrerd, and Wu (2013) argue that a reverse approach to the target-date fund glidepath with an increasing share of equities delivers greater terminal wealth levels for investors. They claim that this approach yields higher wealth levels than the traditional lifecycle approach even at the left tail of the wealth distribution.

In this paper, using nearly a century of data on monthly US equity, corporate and government bond returns, we examine the consequences of alternative popular investment strategies for the decumulation of funds invested for retirement through a defined contribution pension scheme. The findings also apply just as much to endowments, charities, high net wealth individuals, or indeed in any situation requiring regular withdrawals. We analyse sustainable withdrawals by focussing on Perfect Withdrawal Rates (PWR), i.e. the maximum annual withdrawal rate possible if one had perfect foresight of returns, and ran one's wealth down to zero at the end of the period, (see Suarez et al, 2015, Clare et al, 2017). We examine in detail the viability of specific 'safe' withdrawal rates including the '4\%-rule' of Bengen (1994) and also Blanchett et al (2016) for international comparisons. We emphasise the role of Sequence Risk (see Clare et al, 2017) in damaging the possible withdrawal rates and explore ways of enhancing the safe withdrawal experience. Sequence Risk is the possibility of bad portfolio returns occurring at the worst possible time, e.g. just before or after retirement. Much of the retirement literature to-date, in exploring the relationship between sustainable withdrawal, longevity and portfolio investment returns, makes the simplifying assumption of constant year-by-year returns, for example, see Estrada (2017b), footnote 9. This approach is clearly wrong in omitting the role of path dependency.

Basic insight would suggest that diversification across assets might be the route to reducing risk. However, as Lo suggests in the introductory quote above, diversification across asset classes is no longer enough - quite simply, the world is too volatile. This has been dramatically revealed with the abject failure of Target Date and similar Lifestyle investment strategies in the last decade, (see Dhillon et al, 2016). Long-only portfolios, whether passive or active, will inevitably suffer substantial drawdowns at regular (but unpredictable) intervals: even the famous clever and well diversified portfolios of the Harvard and Yale endowments suffered drawdowns of nearly $30 \%$ around 2008/9. The subsequent layoffs of staff and cancellation of capital projects led to a very real impact on these institutions.

We investigate the withdrawal experience associated with Glidepath Investing in TDFs in the US since 1925 for conventional bond-equity portfolios. We find one very powerful conclusion: that smoothing the returns on individual assets by simple absolute momentum or trend following techniques is a potent tool to enhance withdrawal rates, often by as much as $50 \%$ per annum! And, perhaps of even greater social relevance is that it removes the 'left-tail' of unfortunate withdrawal rate experiences, i.e. the bad luck of a poor sequence of returns early in decumulation. We show that diversifying assets over time by switching between an asset and cash in a systematic way is potentially more important for the retirement income 
experience than diversifying one's portfolio across asset classes. We also show that Glidepath investing is only sensible within a few years of the target date. This finding provides succour to enthusiasts for target date investing in the face of the growing hostility in the literature identified above.

Our findings here have direct relevance to some of the key issues facing the retirement industry at present:

i) Should you shift your portfolio composition towards bonds as the start of the decumulation phase begins? Possibly applying Glidepath or Target date investing? We consider the distribution of withdrawal rates associate with different portfolio constructions and time horizons.

ii) Even if the answer to (i) above is in general 'no', is there a short planning horizon at which points you should commence 'gliding'? Even if it is only over the last couple of years?

iii) And can we do better than using (long only) bonds and equities in the portfolio? Crucially, what is the benefit, if any, of switching to cash at times in an effort to reduce drawdowns and smooth returns? Will such a systematic smoothing rule such as trend following offer a superior decumulation journey? The answer is a most persuasive 'yes'.

The paper is set out as follows: in Section 2 we review some of the main issues in retirement a retiree faces, including the choice of decumulation portfolios, the role and nature of Sequence Risk, and the impact of applying trend following techniques to conventional equity and bond portfolios; while Section 3 gives empirical results for US retirement portfolios comprising equities and bonds since 1925. Section 4 examines the whole issue of whether savers should de-risk as they approach retirement, and indeed within retirement, while Section 5 presents our de-risking/glidepath empirical results and Section 6 concludes with a consideration of how divesting (possibly temporarily) to cash stacks up against market timing or derivatives' use in improving the drawdown experience.

\section{Retirement Portfolios and Perfect Withdrawal Rates}

With over 80 million US baby boomers filing for retirement benefits over the next 20 years, with an overwhelming majority relying on defined contributions savings' plans to accumulate and manage their wealth, the issue of appropriate investment strategy is paramount (Social Security Administration, Annual Performance Plan for Fiscal Year 2012). And if in the wider investment universe, active investing is losing out to passive, and yet passive may well be, according to Lo (2012), 'too volatile', with the direct consequence that withdrawal rates will be reduced (see Clare et al, 2017).

The move away from defined benefit (DB) towards defined contribution (DC) and personal savings for pensions is well underway for a wide variety of reasons, comprehensively described in the OECD Pensions Outlook, (2016). This, of course, means that both investment and longevity risk rest with the individual. OECD data on assets and members in DB and DC plans 
from 2000 to 2015 confirm the increasing prominence of DC plans in many OECD countries and, to the extent new schemes have been introduced in recent decades, they have almost entirely been DC schemes, though the exact arrangements differ between countries, (OECD, 2016). Assets in occupational DC plans together with those in personal plans exceeded assets in DB plans in most reporting countries. In the United States, around half of private sector employees have no pension saving, only $2 \%$ have DB plans with $33 \%$ having DC; around $11 \%$ have both DB and DC. In the United Kingdom, the number of members of occupational DC schemes rose from about $2.5 \mathrm{~m}$ to nearly $7.0 \mathrm{~m}$ between 2013 and 2015 . At the same time, membership of occupational DB schemes drifted down from more than $11.5 \mathrm{~m}$ to less than $11.0 \mathrm{~m}$.

The construction of investment portfolios for both phases has been relatively neglected in the study of retirement planning leading to them being described as the 'known unknowns' (Merton, 2014). Indeed, the study of long-term accumulation and decumulation usually treats the two processes as completely separate phenomena. For the former, the emphasis is on changing the riskiness of portfolios as retirement beckons. This usually involves de-risking in the form of glidepath or target-date investing, by raising the proportion in bonds and reducing the percentage in equities, (e.g. see Blanchett et al, 2016, Estrada, 2017b). For the latter, the issue is what percentage of wealth can be withdrawn for consumption each year in a world with uncertain life expectancy and stochastic returns (see Bengen, 1994, Blanchett et al, 2016). Sometimes, of course, the glidepath glides through the retirement date and becomes the decumulation portfolio, though most discussions distinguish between the two for investing purposes. In this paper we analyse the decumulation phase following retirement, by measuring periodic, sustainable withdrawals, i.e. pensions, focussing on Perfect Withdrawal Rates (PWR), i.e. the maximum annual withdrawal rate possible if one had perfect foresight of returns (see Suarez et al, 2015, Clare et al, 2017), and ran one's wealth down to zero at the end of the period. We emphasise the role of Sequence Risk (see Clare et al, 2017) in damaging the possible withdrawal rates and explore ways of enhancing the safe withdrawal experience.

In addition to the spreadsheet exercise used by virtually all academic and commercial researchers which assume constant returns over a decumulation period, an alternative way to assess the sustainable spending possible from a retirement pot is to take a retirement period of, say, 30 years, along with a period of history, say the $20^{\text {th }}$ century, and ask what constant real level could have been withdrawn each year without the retiree running out of money? This approach was pioneered by Bengen (1994) who found that for the typical US portfolio of $50 \%$ equity $/ 50 \%$ government bonds, a lower bound was $4 \%$ of the initial pot (indexed to maintain real purchasing power).

This has been updated and extended by Estrada (2017a), using data on 21 countries over 115 years, and with 11 different combinations of bonds and equities, finds widely varying safe withdrawal rates over time and between countries: the $4 \%$ rule and a $60 / 40$ portfolio would have left substantial bequests much of the time in the US, whereas a $100 \%$ bond portfolio would have run out of money $65 \%$ of the time. If the percentage in stocks was above $50 \%$ then the failure rate was less than $10 \%$. Note that this (and all similar exercises) focus on equities 
and bonds only, presumably as other asset class returns are not available back to 1900 . However, such data restrictions do not rule out making simple switches between equities, bonds and cash if needed. So effectively we have a third asset.

Blanchett et al (2016) provides a relatively comprehensive international overview of safe withdrawal rates for retirees based on both historical returns and forward-looking returns. Overall these findings suggest that financial advisers and retirees in the United Kingdom, for example, should use lower initial safe withdrawal rates than noted in prior research - the lower end of the range now starts towards $2.5 \%$ or $3.0 \%$ and not the previous $4.0 \%$. The generous capital market returns of the prior century that bolstered a comfortable and long-lasting retirement portfolio may give 21 st-century retirees a false sense of security.

As pointed out by Estrada (2017a), many of the empirical exercises in this area focus on varying investment returns and individual longevity but assume the returns are constant over the decumulation period: this, of course, assumes away sequence risk and all the associated realworld problems. Hence experimenting with variations on longevity and (average) returns to deduce sustainable withdrawal rates misses a key point: the order or sequence of returns is of equal importance, but as there is no useful measure of such a concept, it has been largely ignored.

What about diversifying across other asset classes? It might seem trivially obvious that diversification of a portfolio across asset classes-the fabled 'only free lunch in finance'-is the best way for investors to manage risk and enhance returns, and indeed the decumulation journey Mohamed El-Erian, (formerly of PIMCO and currently of Allianz), remarked: 'Diversification alone is no longer sufficient to temper risk. You need something more to manage risk well'.

We begin our empirical analysis by reviewing conventional US retirement portfolios since 1925 using stocks, government and corporate bonds.

\section{The Retirement Experience from Investing in US Equities, Government and Corporate Bonds, 1927-2016.}

\section{(i) Overview: government bond and equity portfolios}

The standard approach to forming US retirement portfolios is to allocate wealth between US equities and government bonds only. Our aim here is to examine how this is affected by allowing shifts into cash, following a trend following rule, as well on a carefully engineered, systematic basis.

It is now increasingly recognised that trend following (otherwise known as Absolute Momentum or time-series momentum, see Moskowitz et al, 2012 and Hurst et al, 2017), has delivered 'strong positive returns and realized a low correlation to traditional asset class returns for more than a century', Hurst et al, (2017). The robustness of this performance over returns 
since 1800 has been recently demonstrated by Baltussen et al (2019). They also show that the statistical significance of this performance is robust to the development of large numbers of potential factors and data snooping.

In its simplest form, Absolute Momentum may involve buying an asset whose price is above a moving average of past prices, often looking back in time say 10 months or a year, yet moving (divesting) this part of a portfolio into cash or Treasury Bills if the asset price falls below the said average. Thus, this involves divesting a proportion of the portfolio into cash though a more sophisticated version would go short the asset rather than into cash itself. ${ }^{1}$

However, we must be careful to distinguish this from the better known traditional crosssectional momentum factor which considers recent asset performance relative to other assets, (DeBondt and Thaler, 1986 and Jegadish and Titman, 1991). The recent results of Baltussen et al (2019) show that trend following subsumes momentum in spanning tests on global returns data since 1800. In addition to raising average returns above a long-only, holding strategy, an Absolute Momentum strategy also typically improves a portfolio's risk adjusted returns (Hurst et al, 2017 and Faber, 2007). ${ }^{2}$

What underlying behaviour can explain the success of trend following? Hurst et al, (2017) suggest that 'a large body of research has shown that price trends exist in part due to longstanding behavioural biases exhibited by investors, such as anchoring and herding'. The intuition for the success of Absolute Momentum is that bear markets occur gradually over many months allowing this strategy to go short in time to benefit from the fall in prices. In practice they show that the strategy has a negative correlation with stocks in negative equity market years and associated periods of downside risk, and performs particularly well in strong up and down years, (also see Baltussen et al, 2019).

Table 1 shows the summary statistics for various combinations of stock and bond portfolios assuming rebalancing takes place at the end of each month (all values are real USD, stock return data from the Shiller database ${ }^{3}$, bond return data from updates of Welch and Goyal (2008) in the Goyal database ${ }^{4}$. Panel A displays conventional portfolios comprising US equities and US government bonds where we see that, as one would expect, as the stock component increases so does the return. The combination, however, with the best risk-return trade-off, based on the Sharpe ratio, is approximately $50 \%$ stocks and $50 \%$ bonds (50-50) with a return

\footnotetext{
${ }^{1}$ See for a recent example, Haghani and White, https://elmfunds.com/tell-them-about-mo/ Bitcoin and Natural Gas and can be considered a factor in some researchers' eyes, just like value and size.

${ }^{2}$ A range of recent research papers have highlighted the potential for Absolute Momentum as an investment strategy, e.g. Moskowitz, Ooi and Pedersen (2012). In their 2014 study Hurst, Ooi, and Pedersen extend this study to 67 markets involving commodities, equity indices, bond markets and currency pairs for the period 1880-2013. Again the authors find that time-series momentum offers a unique diversification opportunity. Empirical evidence supporting time-series momentum for various asset classes is also found in Hutchison and O'Brien (2014), Baltas and Kosowski (2013) and Baltussen et al (2019).

${ }^{3}$ Stock returns data: S\&P 500 index returns from 1926 from Center for Research in Security Press (CRSP) monthend values. Stock returns are the continuously compounded returns on the S\&P 500 index, including dividends. Data from 1871, from Robert Shiller's website, see http://www.econ.yale.edu/ shiller/data.htm.

${ }^{4}$ Long-term government bond yield data from 1919 to 1925 is the U.S. Yield on Long-Term United States Bonds series in the NBER's Macrohistory data base. Yields from 1926 are from Ibbotson's Stocks, Bonds, Bills and Inflation Yearbook, from the Goyal database, see http://www.hec.unil.ch/agoyal/docs/PredictorData2017.xlsx.
} 
of around $5.0 \%$ and volatility of $9.0 \%$. This also gives somewhere close to the portfolio with the smallest maximum real drawdown. This is a remarkably fortuitous coincidence with the actual popular US asset allocation of 60/40 equity/bond and Bengen's (1994) sustainable withdrawal discussions. It is worth pointing out that table 1 also shows, however, that whilst bonds have less volatile returns, they remain subject to maximum drawdowns of a similar order of magnitude to equities. The maximum (real) drawdown for portfolios with $80 \%, 90 \%$ and $100 \%$ bonds are, respectively, $49 \%, 53 \%$ and $67 \%$ ! This serves to undermine the core argument in favour of TDFs.

Panel B shows combinations of stocks and bonds which have had a simple, 10-month trend following rule applied. Following the method of Clare et al (2016), and many others, in the case of stocks, they are in an uptrend if the price is above the 10-month moving average and thus a long position is held. If the price is below the moving average then the weighted funds are assumed to be invested in T-Bills instead. For bonds we adopt the same rule except an index of total return is used. Firstly, we note that applying trend following to bonds has a relatively small impact on the usual performance measures; returns are very slightly lower but so too is volatility. Stocks, however, have a return of $160 \mathrm{bps}$ higher but volatility falls from $15.6 \%$ to just under $10.4 \%$. Maximum drawdown is considerably lower for both asset classes. It is reduced by more than half for the equity-only, and by a third for the bond-only portfolio. Such 'improvements' are consistent with the results for the S\&P500 since 1872, (Clare et al, 2017).

We observe that the combination of the stocks and bonds with the best risk-return trade-off is now approximately $70 \%$ of the former and $30 \%$ of the latter $(70-30 \mathrm{TF})$. This has a return of $6.7 \%$ with volatility of $7.7 \%$ compared to $5.8 \%$ and $11.3 \%$ respectively for the equivalent standard 70-30 portfolio. The trend following portfolio with the closest volatility to the standard 60-40 is 100-0 TF which has a return in excess of $250 \mathrm{bps}$ higher! This is a rather remarkable finding that smoothing a $100 \%$ equity portfolio yields a superior risk-return outcome than diversifying between conventional asset classes: it also hints at the major finding of this paper that 'time-diversification' (in the form of trend following) is more rewarding than diversifying across asset classes.

Trend following, or Absolute Momentum, thus allows investors to take on a greater weighting in stocks for the same risk or a reduced level of risk for the same asset allocation (a volatility of $7.06 \%$ versus $10.08 \%$ for the non-trend adjusted $60-40$ portfolio. This is potentially a powerful practical result in that diversifying between equities and bonds would seem to offer an inferior investment solution than sticking solely with equities and moving in and out of the asset into cash when the trend signals so indicate. Panel B offers a better all-round investing experience by 'smoothing' both the equity and bond returns by simple trend following: the comparable maximum drawdowns are now $32 \%, 35 \%$, and $44 \%$, while volatilities are also much reduced.

Of course, as an aside, one may question whether more sophisticated trend following rules could improve performance further? Different versions of trend adjustment are tested and the results are published in detail in Clare et al (2012). Basically, the results are relatively insensitive to the specific method of adjustment, or indeed the specific choice of look-back period and we apply this finding across asset classes (also in Clare et al, 2016). 


\section{(ii) Comparing Decumulation Strategies: Perfect Withdrawal Rates}

A key comparative metric in assessing the relative qualities of different strategies in the decumulation phase is the Perfect Withdrawal Rate (PWR) described in Section 2 above. Table 2 displays statistics for PWRs (see Suarez et al, 2015 and Clare et al, 2017 for more on this) for a variety of portfolios over a range of decumulation periods:30, 20, 10, 5, 3 and 2 years. The reason we choose very short periods as well as the more usual 20 or 30 years is so that we can assess the benefits of relatively short glidepath strategies. Does there come a point when switching to a high percentage in bonds is a sensible strategy? The answer is indeed yes as we discuss below.

The left-hand side of the table 2 shows values of PWRs from standard investment portfolios holding only equities and bonds while the right-hand side shows values based on the asset classes having had trend following applied to them, in other words 'cash' is introduced as a third asset. Naturally as the length of time the investment pot should last decreases so the PWR rises although this is not a linear relationship with PWRs increasing rapidly as the number of years of decumulation remaining gets smaller. This simple fact is in itself suggests a role for glidepath investing once the planning horizon is reduced to 5 years or less.

Using the 30-year decumulation period (see also Bengen, 1994) as our reference length, i.e. the upper panel in table 2, we see that median PWR for a 100\% long only (i.e. no trend adjustment) equity portfolio is $7.5 \%$ p.a. for the US investor for the period 1925-2016, with maximum and minimum values of $12.8 \%$ and $3.7 \%$ respectively. The lesson here, reinforcing our findings for the period since 1872 (Clare et al, 2017), is that the accident of one's birth has a large effect on the retirement journey if wealth is held predominantly in equity. See Figure 1 for the history of PWRs for different investment strategies. The equivalent numbers if this $100 \%$ equity portfolio has been trend adjusted is $7.9 \%, 12.3 \%$ and $5.1 \%$, suggesting a far better left-tail experience of $5.1 \%$ v $3.7 \%$ for those unfortunate to begin decumulating at the 'wrong' time. But if $100 \%$ equity is rather extreme, what about introducing government bonds? Moving to the more familiar 60-40 savings portfolio (also in the upper panel of table 2), the median PWR is just under $6 \%$ pa with a minimum of $3.6 \%$ with no trend adjustment, but rises to $6.4 \%$ and $4.4 \%$ respectively with smoothing. Effectively the distribution of the PWRs has shifted to the right by applying trend adjustment to the asset returns (see Figure 2 for the US experience since 1925).

A similar shift to the right, improving the left-tail withdrawal experience is present in our analysis for US equities back to 1872 (Clare et al, 2017) and sterling multi asset since 1970 (Clare et al, 2019). It would thus appear that the withdrawal experience in general is enhanced by trend following portfolio adjustment, both for the representative 'median' experience, and, importantly, the lower bound experiences. The only time when long only really 'beats' the smoothed experience is when it is $100 \%$ equity and we are comparing the maximum, far right tail, withdrawals possible. Interestingly, the fabled '4\%' Sustainable Withdrawal Rate over a 30-year decumulation period of Bengen (1994) and others is not supported by results in Table 2 , with a minimum withdrawal rate of $3.57 \%$ for a representative portfolio; this compares to $4.43 \%$ for the smoothed version, comfortably above the $4 \%$ threshold 
The difference between the withdrawal experience for standard stock and bond investment is largest when the PWR length is greatest. For instance, the 30 -year PWR mean is $7.5 \%$ for 100 0 and $4.1 \%$ for $0-100$ compared to $51.6 \%$ and $50.6 \%$ respectively for the 2 -year PWRs. Given that, in the case of the former, the investment pot size is likely to be close to its largest, this is a very significant difference. Furthermore, the minimum PWR for $0-100$ is just $2.4 \%$ compared to $3.7 \%$ for $100-0$ and thus a very conservative asset allocation would have done more harm than good historically over extended periods. The characterisation of the retirement journey is very much in line with Estrada (2017b), Blanchett et al (2016), in reinforcing the benefit of equity exposure in long expected decumulation periods.

As the decumulation length shortens so the possibility of portfolios with large stock allocations underperforming higher bond allocations increases. This is the case for glidepath strategies which we will explore in Sections 4 and 5.

\section{(iii) Absolute Momentum: the desirability of a more concentrated PWR distribution}

Looking at the absolute mometum results in table 2, right-hand panels, the PWRs are generally a little higher than the standard versions due to the slightly greater return on stocks with the filter. We observe that the volatility of the PWRs is considerably lower, however, and this in turn leads to the minimum PWRs being considerably higher than comparable standard portfolios. This is presumably a very desirable property for retirement portfolios and is particularly true for those with high stock weightings. Given that a major consideration in retirement portfolios is not falling below a certain standard of living, this is a useful property. In addition, we, for the most part, no longer find much evidence of increased probabilities of portfolios with high stock weightings underperforming those with higher bond allocations.

This makes the rationale for moving to glidepath strategies essentially redundant. One can still extract the higher PWRs from stocks but now with reduced volatility.

Figure 1 shows how the 20-year PWR values vary over time for $100 \%$ stocks, $100 \%$ bonds and the traditional 60-40 portfolio, both for standard investment and trend following. For a long time, the PWR of stocks was much higher than bonds although this changed somewhat for decumulation periods starting from around 1980. The beginning of a substantial decline in interest rates generated much higher bond returns than previously and hence higher PWRs. Standard and trend following bond PWRs track each other fairly consistently over the entire period. There is much greater deviation between standard and trend following stock PWRs. The big differences occur when a period of large, negative stock returns take place in the early years of decumulation, e.g. see starting points in late 1920's, early 1970's and late 1990's. Periods of generally positive returns often see small outperformance for the standard approach, e.g. late 1980's.

Figure 2 shows the frequency distribution of 20,000 Monte Carlo simulated 20-year PWRs of the same portfolio combinations as Figure 1. We observe that as the portfolio moves away from bonds and towards stocks, so the average PWR increases and the distribution becomes more spread out. It is evident that having a large weighting of bonds when the PWR horizon is long has been a poor strategy. There is a similar chance of achieving a low PWR outcome as most of the other portfolios but without the upside. As one transitions to higher stock weightings, so 
the risk of a low PWR outcomes is considerably reduced by following the trend following method. The trade-off is a small reduction in the possibility of the very highest PWRs compared to standard portfolios.

As a comparison, Figure 3 shows another 20,000 Monte Carlo simulations but this time of 3year PWRs. Following on from our earlier discussion, the outperformance of higher stock weighted portfolios is still present but the difference is less marked now. We note the longer left-hand tail of the 60-40 and 100-0 standard portfolios. There is a clear area which shows an increased risk of PWRs less than 0-100 portfolios. It is avoiding these low PWR outcomes that is the premise for glidepath strategies. If one adopts trend following, however, the probability of observing the poor PWRs is substantially reduced such that there is little reason to transition to anything more conservative than a 60-40 TF portfolio. Trend Following (or similar smoothing of returns) is the key to reducing Sequence Risk and enhancing the decumulation experience.

\section{(iv) Introducing Credit as an Asset Class}

We next consider what would have happened if government bonds were replaced with corporate bonds ${ }^{5}$. Table 3 shows combinations of stocks and corporate bonds both with, and without, trend following. Corporate bonds returned $2.95 \%$ compared to $2.48 \%$ for government bonds with volatility that was nearly $1 \%$ lower. The traditional $60 \%$ stocks, $40 \%$ corporate bond portfolio (60-40C) only returned around $0.1 \%$ p.a. more than $60-40$ with slightly higher volatility such that the Sharpe ratios were the same. A similar pattern emerged when looking at the trend following variants, $60-40 \mathrm{C}$ TF returned nearly $0.2 \%$ p.a. greater than $60-40 \mathrm{TF}$ although this time the volatilities were very similar. There remains minimal difference between the portfolios in terms of Sharpe ratios and maximum drawdown.

Table 4 reprises Table 2 but this time with corporate bonds. The relationships observed previously between stocks, bonds and PWRs remain largely consistent. Using corporate bonds leads to slightly higher PWR rates but the amounts are relatively small. For instance, the mean 30 -year PWR for the $60-40$ portfolio is $6.2 \%$ compared to $6.3 \%$ for $60-40 \mathrm{C}$. The difference remains small for trend- following variants also at $6.6 \%$ and $6.7 \%$ for $60-40 \mathrm{TF}$ and $60-40 \mathrm{C}$ $\mathrm{TF}$. We therefore find that to achieve substantially higher PWRs for a given period, one should shift towards higher stock weightings. The application of trend following does a respectable job of avoiding the very lowest PWR outcomes without sacrificing much of the upside of stocks.

\footnotetext{
${ }^{5}$ Corporate Bond Returns: Long-term corporate bond returns are from Ibbotson's Stocks, Bonds, Bills and Inflation Yearbook and the FRED database, from Goyal database, see http://www.hec.unil.ch/agoyal/docs/PredictorData2017.xlsx
} 


\section{Glidepath Investing and Perfect Withdrawal Rates: What Should be the Role of 'De- risking'?}

Should portfolio composition change as we go through life? So-called Target Date Funds (TDF) and mechanical "glidepath" approaches to de-risking have become popular, accepted practice, both for those approaching retirement and indeed during decumulation. But much of the time the diversification literature tends to ignore an issue which is critical to the discussion here, namely, that investors make periodic contributions to their retirement funds during their working years, or indeed periodic withdrawals during retirement. Hence, the capital accumulated at retirement is a function of both the asset allocation and the size and timing of the contributions. Shiller (2005) was the first to emphasize that investors following a lifecycle strategy choose to have a large exposure to stocks when they are young and their savings are low, and a small exposure to stocks when they are older and their savings are higher. He evaluated the wisdom of this approach through simulations, and found that lifecycle strategies are too conservative, usually underperforming portfolios fully invested in stocks, concluding that these strategies may not be optimal for investors saving for retirement.

Basu and Drew (2009) consider several lifecycle strategies and their mirrors (strategies that remain invested in stocks, bonds, and cash the same amount of time as lifecycle strategies but evolve in the opposite direction, from less aggressive to more aggressive). They find that investors should become more, rather than less aggressive over time. The literature that evaluates the plausibility of lifecycle strategies taking into account the critical role that periodic contributions play on wealth accumulation, besides being scarce, is both recent and largely limited to US data. This is the case with the works of Shiller (2005), Basu and Drew (2009), Ayres and Nalebuff (2010), Basu, Byrne, and Drew (2011), and Arnott (2012).

So, should our portfolio construction veer towards 'reduced risk' as we approach decumulation or even during decumulation? While there is no consensus on the best investment strategy, current debate questions the benefits of the popular target-date or lifecycle funds in the accumulation phase. In a similar vein, Blanchett (2007) compares fixed asset allocations to a wide range of investment paths that reduce the allocation to equity during retirement. He finds that fixed asset allocations provide superior results compared to asset allocations which tend to reduce equity investments in retirement. Arnott, Sherrerd, and Wu (2013) argue that a reverse approach to the target-date fund glidepath with an increasing share of equities delivers greater terminal wealth levels for investors. They yield higher wealth levels than the traditional lifecycle approach even at the left tail of the wealth distribution.

Estrada (2014) provides a comprehensive study of the lifecycle investor glidepath in 19 countries, finding that contrarian strategies provide higher upside potential, more limited downside potential, although with higher uncertainty. Arnott (2012) also argues this case. In a provocative article, he argues that investors would be better off by following a strategy opposite to that implemented by target date funds. In fact, he argues that if investors focus on the capital accumulated at retirement, instead of making their portfolios more conservative, they should make their portfolios more aggressive as retirement approaches, along the lines of Shiller 
(2005). This counterintuitive recommendation follows from a rather obvious but often overlooked fact first highlighted by Shiller (2005): Target date funds expose investors to stocks more in the early years, when the accumulated capital is not large, and less in later years, when the accumulated capital is much larger. Put differently, these funds are aggressive when the portfolio is small and conservative when the portfolio is large, which appears to be suboptimal in terms of capital accumulation.

Despite their growing popularity as long-term savings' vehicles, the idea that conventional target date funds are inherently dangerous has been addressed by Ezra et al (2009) and more recently by Capone and Akant (2016) who note that the great financial crisis wreaked havoc on 2010 target date funds with the 3 largest in the US losing around 30\%+ each in 2008: this unfortunate turn of events reflects sequence risk as outlined above; namely poor (if not disastrous) returns in the investment portfolio occurring at exactly the worst time for the longterm saver: i.e. just before retirement. Capone and Akant (2016) identify 'too much equity' and not enough diversification across sources of risk premia as the fundamental problems here and suggest integrating their multi-asset trend following strategy with conventional target date fund strategies. Although trend following appears in the title of their paper, they are not advocating the trend following, 'smoothing' technique, but rather they add their multi-asset trend following investing solution ('fund') to existing target date fund solutions (i.e. an extra diversifying asset which happens to be a conventional trend following Commodity Trade Advisors (CTA) fund). While any diversification is to be welcomed, and meets their first objection to simple target date funds with limited asset diversification, it still does not address the underlying problem of sequence risk, the potentially large drawdowns at the 'wrong' time. They add up to $15 \%$ of portfolio value in the form of their CTA to conventional target date fund allocations, still leaving the bond allocation vulnerable to the next (unforeseeable) secular shift upwards in interest rates.

However, their acknowledgement that maximum loss is much reduced relative to conventional target date funds is a step in the right direction in addressing sequence risk. In anticipation of our proposal later in this paper and elsewhere, we would advocate subjecting all asset classes to smoothing by trend following (see Faber, 2007, Clare et al, 2016), rather than just adding a CTA component to an otherwise long only conventional target date fund allocation. Indeed, as also advocated by Capone and Akant (2016), an additional benefit to smoothing is the longrun extra performance (both risk-adjusted and absolute) due to trend following as evidenced across a wide range of asset classes by Faber (2007) and Clare et al (2016).

In practical terms, Bengen (1994) advises that if future market returns follow behaviour as seen in the past, then a retirement portfolio should hold a 50 to $75 \%$ allocation to equities. Milevsky and Huang (2011) and Ameriks, Veres, and Warshawsky (2001) demonstrate through simulation the need for holding a substantial equity allocation in a retirement portfolio. Cooley, Hubbard, and Walz (2011) propose that at least $50 \%$ of a retirement portfolio should be invested in equities and their findings show increased sustainability of the fund as it tilts more towards equities. They explain that the presence of bonds is mainly to restrain portfolio volatility and provide liquidity to cover an investor's living expenses. 
The lifecycle strategy holds a high allocation to equities at the onset but moves towards less volatile assets, such as bonds and cash with increasing age. This is the default investment option in many employer-sponsored and individual retirement plans (see Charlson and Lutton, 2012). In Australia, lifecycle funds are increasing rapidly, expected to catch up or surpass the U.S. in the next decade (OECD, 2016). In the US, plan sponsors have flocked to the target-date fund (TDF) as a solution for participants to save for retirement. Regulatory direction has anointed the TDF as a Qualified Default Investment Alternative (QDIA), which has prompted substantial and ongoing inflows to these types of savings vehicles across the DC plan universe. Callan Associates' DC Index supports the notion of both the increasing prevalence and utilization of TDFs. As of the third quarter of 2015, Callan estimated that $88 \%$ of U.S. DC plans tracked included TDFs, with an average allocation to TDFs of $30 \%$. Also in the third quarter of 2015 , an estimated $61 \%$ of new cash flows to DC plans were allocated to TDFs. Though TDFs have become the most popular DC investing vehicle, we believe that several shortcomings should be addressed to more reliably maximize retirement outcomes.

The lifecycle approach is implemented with the aim of avoiding insufficient diversification as well as to avoid investment choices that may be age-inappropriate. While it undoubtedly achieves these aims, the relevance of having investments following a predetermined glidepath solely dependent on age appears to us simplistic. Important factors such as account balance, gender, marital status, retirement income expectations and life expectancy improvements influence the asset allocation decision. It is clear from this discussion that there is no consensus as yet on de-risking both towards and during retirement.

\section{Glidepath Investing and Withdrawal Rates}

As we saw in Section 3 above a useful comparative metric in assessing the relative qualities of different strategies in the decumulation phase is the Perfect Withdrawal Rate (PWR) as discussed by Suarez et al (2015) and Clare et al (2017).

We examine the distribution of withdrawal rates from $100 \%$ equity, $100 \%$ bond and $60-40$ portfolios in more detail in Tables 5-7, considering in addition a variety of planning horizons to capture the idea of glidepath investing, from 30 years down to 2 years. Looking at the median results in Table 5 we observe that the 100\% Stocks portfolio delivers a higher PWR in every case than the 60-40 portfolio which in turn delivers a higher value than the $100 \%$ Bond portfolio. When one looks at the minimum value columns a different picture emerges, however. The 60-40 has a higher PWR than 100\% Stocks from Year 23 and this persists as the decumulation period shortens. We also observe that from Year 12 the $100 \%$ Bond portfolio has a higher PWR than 60-40. This is less consistent though, with 60-40 having higher values between Years 8 to 5 inclusive.

Table 6 shows the same set of results but this time with trend following applied to each of the asset classes. Compared to the standard results, we note that the average maximum PWR for $100 \%$ Stocks TF is around 40 bps lower and fairly similar for $60-40 \mathrm{TF}$ and $100 \%$ Bonds TF. The average median value is around 25 bps higher for $100 \%$ Stocks TF, however, and this is replicated for the other two portfolios. We observe the most significant differences in the 
minimum value columns. The 30 Year 100\% Stocks PWR is 5.13\% compared to just $3.69 \%$ for the standard equivalent. Substantial differences are observed across every year. There is much less variation between the standard and trend following in the case of $100 \%$ Bonds and thus the 60-40 TF reflects the combination of these two. When we compared the minimum values within Table 6, the 60-40 TF value first surpasses 100\% Stocks in Year 9, some 14 years later than in Table 5, and remains greater in all remaining years apart from Year 3 . The minimum value for $100 \%$ Bonds TF never exceeds that of 60-40 TF and indeed only exceeds $100 \%$ Stocks TF in the single Year 5. What this means from an investment context is that investors wishing to follow a glidepath strategy can stay in stocks for longer by adopting a trend following approach and hence have the possibility to earn higher returns whilst also reducing the risk of the very worst outcomes.

Figure 4 shows the asset allocation to stocks that would have produced, with the benefit of hindsight, the highest minimum PWR for each number of decumulation years remaining. This is in effect the ideal asset allocation for the most conservative investor since it would have given the least bad outcome in every case. The first point of note is that investing heavily in bonds when there was a long decumulation period remaining would have been a long way from optimal. The most conservative standard portfolio had around $85 \%$ in stocks with 30 years of decumulation remaining falling to around $70 \%$ when there were 20 years left. After this the switch from stocks to bonds becomes more dramatic and also, we note that the transition becomes a lot less smooth in the last 10 years. In the case of trend following, we find that the optimal portfolio for the worst-case scenario remains at 100\% all the way to Year 10 apart from Year 13. Given the higher returns to stocks this looks very favourable. Again, from Year 10 the transition becomes rather choppy but a glidepath to somewhere around $65-70 \%$ Stocks looks a reasonable conclusion. This is much higher than the standard approach where one would have been almost exclusively in bonds.

In an attempt to provide glidepaths which are somewhat smoother, and also for investors of varying risk tolerances, we turn to Monte Carlo simulations. We create 101 portfolios, moving from stocks to bonds in 1\% increments, and run 100,000 simulations for each calculating the PWR in each case. For each asset allocation we calculate the following PWR percentiles: $1^{\text {st }}$, $5^{\text {th }}, 10^{\text {th }}, 25^{\text {th }}$ and $50^{\text {th }}$. We then look to see which allocation gives the highest value for each percentile and this becomes the basis for the glidepath. The $1^{\text {st }}$ percentile is thus in many ways similar to a $1 \%$ VaR calculation in that it calculates the best asset allocation that gave a $1 \%$ chance of getting a lower PWR. Less risk-averse investors would look to move up the percentiles and adopt a different glidepath.

Figure 5 shows the approximate glidepaths for standard stock-bond allocations expressed as the percentage of the portfolio invested in stocks. Firstly, we observe that at 30-year PWRs the stock proportion is much lower than in Figure 4. This is due to the returns of bonds being much higher during the last 30 years of the return sequence than the beginning. As a result, they appeared disproportionately near the end of a lot of the PWR calculations when a large amount of decumulation had already occurred and thus had little impact. In the case of the Monte Carlo simulations, they are now randomly dispersed and hence have a greater influence on the outcomes. That aside, the pattern is one of a relatively linear transition from stocks to bonds 
from 30 to 20 years before the pace starts to accelerate, and particularly so in the last 10 years. We observe that as risk aversion falls so the percentage allocation to stocks increases. The $1^{\text {st }}$ percentile starts at around 35\% stocks and ends with near $15 \%$ compared to over $80 \%$ at the beginning for the $25^{\text {th }}$ percentile and declining to just under $40 \%$. The $50^{\text {th }}$ percentile remains at $100 \%$ stocks for virtually the entire time.

Figure 6 displays the same set of glidepaths but this time for stocks and bonds with trend following applied. Consistent with our earlier findings, the proportion of the portfolio held in stocks is much higher. The $1^{\text {st }}$ percentile glidepath starts at over $80 \%$ and finishes around $40 \%$; this is higher than the standard portfolio begins at Year 30. All of the other percentiles commence at $100 \%$ Stocks and transition down in a similar pattern with the switch to bonds accelerating in the last few years. In the case of the $25^{\text {th }}$ percentile glidepath this only begins around Year 7 . Once again, the $50^{\text {th }}$ percentile is resolutely $100 \%$ in equity.

Table 7 displays the effects of the different glidepaths in terms of the PWRs garnered. In the case of the $1^{\text {st }}$ percentile the PWR using trend following is $4.17 \%$ compared to just $3.01 \%$ for the standard approach. This effectively equates to a $38 \%$ higher retirement income in the case of the former. Substantial differences remain across all percentiles and decumulation periods until the latter gets short and the level of risk tolerance increases. Trend following increases the proportion of the portfolio that can be invested in equities and thus earn higher returns.

\section{Concluding Comments and Discussion}

The application of an absolute momentum or trend following overlay on the assets in a drawdown retirement portfolio reduces maximum drawdowns across asset classes, countries and historical periods (see Clare et al, 2017 and 2019, Faber 2007), reducing sequence risk and potentially improving the retirement journey, but why not use derivatives to achieve similar ends? But as AQR emphasise, "Unfortunately, in the typical use case, put options are quite ineffective at reducing drawdowns versus the simple alternative of statically reducing exposure to the underlying asset." (Israelov, 2017, p 1,).

Basically, in the case of equities, unless the options' purchases and their maturities are timed precisely right around equity drawdowns of uncertain length, then they may result in little downside protection, and even make things worse by increasing rather than decreasing drawdowns and volatility per unit of expected return.

Is buying protective puts combined with the S\&P500 equity portfolio an effective tail hedge? Israelov (2017) shows that portfolios that are protected with put options have worse peak-totrough drawdown characteristics per unit of expected return than portfolios that have instead simply reduced their equity exposure in order to reduce risk.

So changing portfolio allocation between the risky asset and cash (so-called 'divestment') will give a better result than buying put protection, unless the drawdown coincides with the option expiry cycle. In fact the paper suggests that investing $40 \%$ in equity and $60 \%$ in cash has given 
similar returns as the protected puts strategy but with under half the volatility and much improved peak-to -trough drawdown experience.

As Israelov (2017) states: “For those who are concerned about their equity's downside risk, reducing their equity position is significantly more effective than buying protection. Sized to achieve the same average return, divesting has lower drawdowns, lower volatility, lower equity beta, and a higher Sharpe ratio than does buying put options."

This approach also echoes the views of Ilmanen (2016). He refers to index put buying as protection for equity portfolios as (looking at historical data) "roughly a minus one Sharpe strategy". Of course, very fast bear markets and crashes can be protected against by using puts, but this is so expensive relative to the slow crash alternative (moving into cash) which is so successful in the long run: "Trend following has a clear positive Sharpe ratio, and it has done well in most of the historical bear markets over the past hundred years'. Direct hedging is costly and only delivers value when combined with the ability to predict short-term market crashes and unwind the positions quickly after a crash.

How about more sophisticated timing mechanisms for buying protection? Strub (2013) introduces an algorithm for tail risk hedging and compares it with using Extreme Value Theory (EVT) to estimate Conditional Value at Risk (CVaR), and applies it to the S\&P 500 and MSCI Emerging Markets equity indexes between 2000 and 2012. Performance is compared to cash and options-based tail hedging strategies. The cash-based methods are shown to significantly increase risk-adjusted returns and reduce drawdowns, while the options-based strategy suffers a decrease in performance from 2003 onwards due to the increase in the cost of puts with respect to calls.

It would seem then that divesting (albeit temporarily) offers a much better solution to reducing drawdowns (i.e. managing tail risk) than either buying puts systematically or trying to time their purchases using conditioning information as in Strub (2013), though of course there are an infinity of such alternatives. Unless one knows when a 'fast crash' is about to occur and can time the option purchase cycle to good effect, then switching to cash via a trend following rule appears to be the best solution.

However, there is an industry-wide aversion by advisers to recommending holding large proportions in cash even when the evidence is stacked up in its favour: they feel they can hardly charge fees for advocating cash holdings whereas in fact this form of timely diversification may well be the only sensible game in town.

Our results have shown the impact on retirees of smoothing investment returns through trend adjustment (i.e. divesting at times into cash) over a long period of US equity and bond returns. We find that the withdrawal experience from conventional equity/bond portfolios can be substantially enhanced by applying these smoothing techniques, effectively creating a much higher lower bound for withdrawal rates in the $20^{\text {th }}$ century $(4.4 \%$ pa versus $3.6 \%$ p.a. for the popular 60-40 allocation with withdrawals lasting 30 years), and also improving withdrawal 
rates for the 'average' experience ( $6 \%$ $6.4 \%$, see Table 2$)$. In all cases strategies targeting a set volatility (as is popular with retirement consultants) allows far higher equity proportions and consequent withdrawal rates for a given volatility level (or 'bucket').

The failure of Target Date Funds and Glidepath Investing, with the associated disastrous experience for such strategies targeting 2010 among the largest commercial providers (see Dhillon et al, 2016 and Ezra, 2009), prompted research on alternative approaches including maintaining constant proportions of equities and bonds, or indeed reversing the glide proportions, have been explored by, for example, Estrada (2014). Our findings for varying decumulation period lengths suggests that unless one is very risk averse it would only appear sensible to apply conventional glidepath strategies towards the last few years of decumulation, and then only move towards a 50-50 equity-bond allocation.

Israelov (2017) emphasises the possible advantages of devoting a percentage of the portfolio to trend following assets which are robust to large equity drawdowns and are largely uncorrelated with conventional assets. They have in mind a CTA 'hedge' fund, for example, and possibly allocating to it up to $15 \%$ of wealth. This certainly improves the experience in reducing drawdowns (and hence Sequence Risk) but begs the question as to why stop at 15\% - why not consider the advantages of trend adjustment for the whole portfolio? 


\section{References}

Ameriks, J., Veres, R., and Warshawsky, M. (2001). Making Retirement Income Last a Lifetime, Journal of Financial Planning, 14(12), 60-76.

Arnott, R., (2012). The Glidepath Illusion, Research Affiliates Fundamentals, September, 1-5.

Arnott, R., Sherrerd, K., and Wu, L., (2013). The Glidepath Illusion....and Potential Solutions, Journal of Retirement, 1(2), 13-28.

Ayres, I. and Nalebuff, B., (2010). Lifecycle Investing - A New, Safe and Audacious Way to Improve the Performance of Your Retirement Portfolio. New York: Basic Books.

Baltas, N. and Kosowski, R., (2013). Momentum Strategies in Futures Markets and Trend following Funds, Working Paper, Imperial College Business School.

Baltussen, G., Swinkels, L. and Van Vliet, P. (2019). Global Factor Premiums, SSRN, https://papers.ssrn.com/sol3/papers.cfm?abstract id=3325720.

Basu, A. and Drew M. (2009). Portfolio Size Effect in Retirement Accounts: What Does it Imply for Lifecycle Asset Allocation Funds?, Journal of Portfolio Management, 35(3), 61-72.

Basu, A., Byrne, A. and Drew, M. (2011). Dynamic Lifecycle Strategies for Target Date Retirement Funds, Journal of Portfolio Management, 37(2), 83-96.

Bengen, W. P. (1994), Determining Withdrawal Rates Using Historical Data, Journal of Financial Planning, 7(1), 171-180.

Blanchett, D., (2007). Dynamic Allocation Strategies for Distribution Portfolios; Determining the Optimal Distribution Glide Path, Journal of Financial Planning, December, 68-81.

Blanchett, D., Buffenoir, M., Kemp, D. and Watt, S. (2016). Safe Withdrawal Rates for Retirees in the United Kingdom, Morningstar Research.

Capone, R. and Akant, A. (2016). Trend Following Strategies in Target-Date Funds, AQR Capital Management Working Paper.

Charlson, J., and Lutton, L., (2012). Target-Date Series Research Paper: 2012 Industry Survey, Morningstar Fund Resarch, May, 1-58.

Clare, A., Seaton, J., Smith, P.N., and S.H. Thomas, (2013). Breaking in to the Blackbox: Trend Following, Stop Losses and the Frequency of Trading - The Case of the S\&P500, Journal of Asset Management, Vol. 14, 182-194.

Clare, A., Seaton, J., Smith, P.N., and Thomas S., (2016). The Trend is Our Friend: Risk Parity, Momentum and Trend Following in Global Asset Allocation, Journal of Behavioral and Experimental Finance. 9, 63-80.

Clare, A., Seaton, J., Smith, P.N., and Thomas S., (2017). Reducing sequence risk using trend following investment strategies and the CAPE, Financial Analysts Journal, 73(4), 91-103.

Clare, A., Seaton, J., Smith, P.N., and Thomas S., (2019). Can sustainable withdrawal rates be enhanced with trend following?, SSRN,

https://papers.ssrn.com/sol3/papers.cfm?abstract id=3019089.

Cocco, J., Gomes, F., and Maenhoiut, P., (2005). Consumption and Portfolio Choice over the Life cycle, Review of Financial Studies, 18, 491-533. 
Cooley, P., Hubbard, C., and Walz D., (2011). Portfolio Success Rates: Where to Draw the Line, Journal of Financial Planning, 24, 48-60.

DeBondt, W., and Thaler, R., (1986). Further Evidence on Investor Overreaction and Stock Market Seasonality, Journal of Finance, 42(3), 557-581.

Dhillon, J., Ilmanen, A., and Liew, J., (2016). Balancing on the Life Cycle: Target-Date Funds Need Better Diversification, Journal of Portfolio Management, 42, 4.

Donaldson, S., Kinniry, Jr., F., Ameriks, J., Aliaga-Díaz, R., Redding, B., and Patterson, A., (2012). Vanguard's Approach to Target-Date Funds, Vanguard Research, November, 1-20.

Estrada, J. (2014). The Glidepath Illusion: An International Perspective, Journal of Investing, 25,2 (2016), 28-54.

Estrada, J. (2017a). Refining the Failure Rate, Journal of Retirement, 4(3), 63-76.

Estrada,J. (2017b). Maximum Withdrawal Rates: An Empirical and Global Perspective, SSRN 2914078.

Ezra, D., Collie, B., and Smith M., (2009). The Retirement Plan Solution: The Reinvention of Defined Contribution. John Wiley \& Sons.

Faber, M., (2007). A Quantitative Approach to Tactical Asset Allocation, Journal of Wealth Management, 16, 69-79.

Hurst, B., Ooi, Y., and Pedersen, L.H. (2017). A century of evidence on trend following. Journal of Portfolio Management, 44, 1.

Hutchison, M., and O'Brien, J. (2014). Is This Time Different? Trend following and Financial Crises, Journal of Alternative Investments, 17(2), 82-102.

Jegadeesh, N. and Titman, S. (1993). Returns to Buying Winners and Selling Losers: Implications for Stock Market Efficiency, Journal of Finance, 48(1), 65-91.

Israelov, R., (2017). The Elusive Benefits of Protective Puts, AQR Capital Management Working Paper.

Ilmanen, A. (2016). Smart Investing in an Environment of Low Expected Returns, Journal of Investment Consulting, 17(2), 4-12.

Lo, A. (2012), Why buy and hold doesn't work anymore, CNN Money, interview, http://money.cnn.com/2012/03/02/pf/efficient_market.moneymag/index.htm

Merton, R., (1969). Lifetime Portfolio Selection under Uncertainty, Review of Economics and Statistics, 51(3), 247-257.

Merton, R., (1971). Optimum Consumption and Portfolio Rules in a Continuous-Time Model, Journal of Economic Theory, 3(4), 373-413.

Merton, R., (2014). The Crisis in Retirement Planning, Harvard Business Review, July-August.

Milevsky, M. and Huang, H., (2011). "Spending Retirement on Planet Vulcan: The Impact of Longevity Risk Aversion on Optimal Withdrawal Rates", Financial Analysts Journal, 67(2), 45-58.

Moskowitz, T., Ooi, Y.H., and Pedersen, L., (2012). Time Series Momentum, Journal of Financial Economics, 104(2), 228-250. 
OECD, (2016). Pensions Outlook, Paris.

Samuelson, P., (1969). Lifetime Portfolio Selection by Dynamic Stochastic Programming, Review of Economics and Statistics, 51(3), 239-246.

Shiller, R., (2005). Life-Cycle Portfolios as Government Policy, The Economists' Voice, 2, 1, $1-14$.

Strub, I.S., (2013), Tail Hedging Strategies, The Cambridge Strategy (Asset Management) Ltd, mimeo.

Suarez, E.D., Suarez, A. and Walz D.T., (2015), The Perfect Withdrawal Amount: A Methodology for Creating Retirement Account Distribution Strategies, Trinity University Working Paper.

Welch, I, and Goyal, A., (2008), "A comprehensive look at the empirical performance of equity premium prediction", Review of Financial Studies, 21 (4), 1455 - 1508. 
Table 1

\begin{tabular}{|c|c|c|c|c|c|c|c|c|c|c|c|}
\hline \multicolumn{12}{|c|}{ Summary Statistics for Stock and Bond Portfolios 1927-2016 } \\
\hline Stocks (\%) & 100 & 90 & 80 & 70 & 60 & 50 & 40 & 30 & 20 & 10 & 0 \\
\hline Bonds (\%) & 0 & 10 & 20 & 30 & 40 & 50 & 60 & 70 & 80 & 90 & 100 \\
\hline \multicolumn{12}{|l|}{ A: Standard } \\
\hline Real Annual Return (\%) & 6.81 & 6.52 & 6.20 & 5.84 & 5.46 & 5.04 & 4.59 & 4.10 & 3.59 & 3.05 & 2.48 \\
\hline Real Annualised Volatility (\%) & 15.66 & 14.14 & 12.67 & 11.31 & 10.08 & 9.03 & 8.25 & 7.81 & 7.76 & 8.11 & 8.83 \\
\hline Sharpe Ratio & 0.40 & 0.42 & 0.45 & 0.47 & 0.49 & 0.50 & 0.49 & 0.46 & 0.40 & 0.31 & 0.22 \\
\hline Maximum Real Drawdown (\%) & 76.80 & 71.57 & 65.34 & 57.95 & 49.21 & 40.49 & 42.65 & 45.30 & 49.10 & 52.87 & 67.24 \\
\hline \multicolumn{12}{|l|}{ B: Trend Following } \\
\hline Real Annual Return (\%) & 8.39 & 7.85 & 7.31 & 6.74 & 6.17 & 5.58 & 4.98 & 4.36 & 3.73 & 3.09 & 2.44 \\
\hline Real Annualised Volatility (\%) & 10.44 & 9.46 & 8.55 & 7.74 & 7.06 & 6.54 & 6.24 & 6.18 & 6.38 & 6.80 & 7.40 \\
\hline Sharpe Ratio & 0.75 & 0.78 & 0.79 & 0.80 & 0.80 & 0.77 & 0.71 & 0.62 & 0.50 & 0.38 & 0.26 \\
\hline Maximum Real Drawdown (\%) & 34.88 & 32.02 & 29.51 & 27.57 & 27.33 & 27.34 & 27.54 & 28.98 & 32.12 & 35.18 & 44.34 \\
\hline
\end{tabular}


Table 2

Perfect Withdrawal Rates for Stock and Bond Combinations: 1927-2016

\begin{tabular}{|c|c|c|c|c|c|c|c|c|c|c|c|c|}
\hline \multirow[b]{2}{*}{ Stock(\%) } & \multicolumn{6}{|c|}{ Standard } & \multicolumn{6}{|c|}{ Trend Following } \\
\hline & 100 & 80 & 60 & 40 & 20 & 0 & 100 & 80 & 60 & 40 & 20 & 0 \\
\hline Bond(\%) & 0 & 20 & 40 & 60 & 80 & 100 & 0 & 20 & 40 & 60 & 80 & 100 \\
\hline \multicolumn{13}{|c|}{ 30-year PWRs } \\
\hline Mean & 7.51 & 6.86 & 6.18 & 5.48 & 4.77 & 4.09 & 8.19 & 7.41 & 6.63 & 5.87 & 5.14 & 4.45 \\
\hline Median & 7.50 & 6.66 & 5.97 & 5.23 & 4.05 & 3.17 & 7.88 & 7.09 & 6.37 & 5.24 & 4.58 & 3.83 \\
\hline Max & 12.81 & 10.96 & 10.85 & 10.64 & 10.33 & 9.92 & 12.32 & 11.09 & 10.88 & 10.61 & 10.27 & 9.87 \\
\hline Min & 3.69 & 3.71 & 3.57 & 3.38 & 3.14 & 2.42 & 5.13 & 4.88 & 4.43 & 3.91 & 3.32 & 2.57 \\
\hline StDev & 2.55 & 2.06 & 1.77 & 1.70 & 1.75 & 1.83 & 2.01 & 1.71 & 1.57 & 1.57 & 1.66 & 1.78 \\
\hline \multicolumn{13}{|c|}{ 20-year PWRs } \\
\hline Mean & 9.01 & 8.47 & 7.90 & 7.30 & 6.68 & 6.04 & 9.55 & 8.90 & 8.24 & 7.59 & 6.94 & 6.30 \\
\hline Median & 8.78 & 8.68 & 7.86 & 7.08 & 6.08 & 5.10 & 9.75 & 8.87 & 8.01 & 7.12 & 6.40 & 5.59 \\
\hline Max & 15.06 & 12.68 & 12.48 & 12.31 & 12.05 & 11.70 & 14.27 & 12.81 & 12.47 & 12.30 & 12.08 & 11.81 \\
\hline Min & 4.28 & 4.42 & 4.39 & 4.22 & 4.01 & 3.75 & 5.81 & 5.59 & 5.33 & 5.01 & 4.55 & 3.79 \\
\hline StDev & 2.84 & 2.36 & 2.05 & 1.94 & 1.97 & 2.06 & 2.20 & 1.93 & 1.80 & 1.79 & 1.87 & 1.99 \\
\hline \multicolumn{13}{|c|}{ 10-year PWRs } \\
\hline Mean & 13.13 & 12.81 & 12.45 & 12.04 & 11.60 & 11.12 & 13.85 & 13.34 & 12.82 & 12.27 & 11.72 & 11.16 \\
\hline Median & 13.60 & 12.94 & 12.34 & 11.86 & 11.57 & 10.76 & 13.46 & 13.15 & 12.60 & 11.99 & 11.25 & 10.46 \\
\hline Max & 20.21 & 18.06 & 17.23 & 16.98 & 17.00 & 16.95 & 20.27 & 18.32 & 17.25 & 17.11 & 16.91 & 16.68 \\
\hline Min & 7.00 & 7.27 & 7.50 & 7.68 & 7.81 & 7.83 & 9.15 & 9.03 & 8.89 & 8.73 & 8.40 & 7.82 \\
\hline StDev & 3.31 & 2.73 & 2.30 & 2.06 & 2.03 & 2.19 & 2.57 & 2.29 & 2.10 & 2.01 & 2.03 & 2.11 \\
\hline \multicolumn{13}{|c|}{ 5-year PWRs } \\
\hline Mean & 22.66 & 22.41 & 22.12 & 21.79 & 21.42 & 21.01 & 23.28 & 22.86 & 22.43 & 21.97 & 21.49 & 20.99 \\
\hline Median & 22.86 & 22.62 & 22.31 & 21.92 & 21.54 & 20.96 & 22.84 & 22.71 & 22.30 & 21.82 & 21.36 & 20.74 \\
\hline Max & 31.56 & 29.92 & 28.82 & 27.68 & 26.65 & 26.79 & 31.76 & 29.42 & 28.30 & 27.34 & 27.05 & 26.72 \\
\hline Min & 13.53 & 14.85 & 15.72 & 16.57 & 16.63 & 15.54 & 16.27 & 16.90 & 16.85 & 16.72 & 16.58 & 16.36 \\
\hline StDev & 4.19 & 3.43 & 2.78 & 2.34 & 2.18 & 2.34 & 3.04 & 2.64 & 2.32 & 2.12 & 2.08 & 2.17 \\
\hline \multicolumn{13}{|c|}{ 3-year PWRs } \\
\hline Mean & 35.58 & 35.38 & 35.13 & 34.85 & 34.53 & 34.18 & 36.06 & 35.72 & 35.36 & 34.98 & 34.58 & 34.16 \\
\hline Median & 36.02 & 35.90 & 35.50 & 35.01 & 34.57 & 34.22 & 35.79 & 35.54 & 35.31 & 34.94 & 34.59 & 34.01 \\
\hline Max & 46.10 & 43.88 & 41.64 & 41.14 & 41.11 & 41.05 & 46.10 & 43.88 & 41.63 & 41.14 & 41.11 & 41.05 \\
\hline Min & 23.28 & 24.73 & 26.18 & 27.62 & 28.37 & 28.54 & 29.24 & 29.10 & 28.96 & 28.80 & 28.64 & 28.47 \\
\hline StDev & 4.87 & 3.98 & 3.20 & 2.63 & 2.40 & 2.57 & 3.34 & 2.84 & 2.44 & 2.19 & 2.14 & 2.29 \\
\hline \multicolumn{13}{|c|}{ 2-year PWRs } \\
\hline Mean & 51.64 & 51.50 & 51.32 & 51.12 & 50.89 & 50.62 & 52.00 & 51.76 & 51.49 & 51.21 & 50.92 & 50.60 \\
\hline Median & 52.70 & 52.12 & 51.74 & 51.21 & 50.91 & 50.52 & 51.98 & 51.88 & 51.35 & 50.92 & 50.65 & 50.31 \\
\hline Max & 60.51 & 58.64 & 56.97 & 56.73 & 56.72 & 57.48 & 59.87 & 58.33 & 56.76 & 56.54 & 56.94 & 57.48 \\
\hline Min & 37.78 & 41.44 & 43.16 & 44.86 & 45.42 & 45.31 & 45.87 & 46.33 & 46.43 & 46.12 & 45.80 & 44.08 \\
\hline StDev & 4.75 & 3.87 & 3.10 & 2.55 & 2.37 & 2.61 & 3.21 & 2.71 & 2.31 & 2.07 & 2.06 & 2.27 \\
\hline
\end{tabular}


Table 3

\begin{tabular}{|c|c|c|c|c|c|c|c|c|c|c|c|}
\hline \multicolumn{12}{|c|}{ Summary Statistics for Stock and Corporate Bond Portfolios 1927-2016 } \\
\hline Stocks (\%) & 100 & 90 & 80 & 70 & 60 & 50 & 40 & 30 & 20 & 10 & 0 \\
\hline Bonds (\%) & 0 & 10 & 20 & 30 & 40 & 50 & 60 & 70 & 80 & 90 & 100 \\
\hline \multicolumn{12}{|l|}{ A: Standard } \\
\hline Real Annual Return (\%) & 6.81 & 6.54 & 6.25 & 5.93 & 5.58 & 5.21 & 4.81 & 4.38 & 3.93 & 3.45 & 2.95 \\
\hline Real Annualised Volatility (\%) & 15.66 & 14.25 & 12.88 & 11.59 & 10.39 & 9.32 & 8.44 & 7.81 & 7.49 & 7.52 & 7.90 \\
\hline Sharpe Ratio & 0.40 & 0.42 & 0.44 & 0.47 & 0.49 & 0.50 & 0.51 & 0.49 & 0.46 & 0.39 & 0.31 \\
\hline Maximum Real Drawdown (\%) & 76.80 & 71.81 & 65.88 & 58.87 & 50.61 & 40.91 & 41.35 & 43.19 & 45.98 & 49.58 & 61.13 \\
\hline \multicolumn{12}{|l|}{ B: Trend Following } \\
\hline Real Annual Return (\%) & 8.39 & 7.90 & 7.39 & 6.88 & 6.35 & 5.81 & 5.26 & 4.70 & 4.13 & 3.55 & 2.96 \\
\hline Real Annualised Volatility (\%) & 10.44 & 9.50 & 8.62 & 7.80 & 7.07 & 6.47 & 6.02 & 5.76 & 5.72 & 5.91 & 6.30 \\
\hline Sharpe Ratio & 0.75 & 0.78 & 0.80 & 0.81 & 0.82 & 0.82 & 0.79 & 0.73 & 0.63 & 0.51 & 0.39 \\
\hline Maximum Real Drawdown (\%) & 34.88 & 31.78 & 29.32 & 27.39 & 27.12 & 26.89 & 27.65 & 31.21 & 34.67 & 38.04 & 41.43 \\
\hline
\end{tabular}


Table 4

Perfect Withdrawal Rates for Stock and Corporate Bond Combinations: 1927-2016

\begin{tabular}{|c|c|c|c|c|c|c|c|c|c|c|c|c|}
\hline & \multicolumn{6}{|c|}{ Standard } & \multicolumn{6}{|c|}{ Trend Following } \\
\hline Stock(\%) & 100 & 80 & 60 & 40 & 20 & 0 & 100 & 80 & 60 & 40 & 20 & 0 \\
\hline Corp(\%) & 0 & 20 & 40 & 60 & 80 & 100 & 0 & 20 & 40 & 60 & 80 & 100 \\
\hline \multicolumn{13}{|c|}{ 30-year PWRs } \\
\hline Mean & 7.51 & 6.91 & 6.27 & 5.62 & 4.96 & 4.32 & 8.19 & 7.45 & 6.70 & 5.97 & 5.26 & 4.58 \\
\hline Median & 7.50 & 6.74 & 6.16 & 5.38 & 4.29 & 3.40 & 7.88 & 7.13 & 6.38 & 5.33 & 4.57 & 3.97 \\
\hline Max & 12.81 & 11.01 & 10.97 & 10.84 & 10.62 & 10.30 & 12.32 & 11.18 & 11.05 & 10.86 & 10.62 & 10.30 \\
\hline Min & 3.69 & 3.76 & 3.65 & 3.51 & 3.28 & 2.53 & 5.13 & 4.89 & 4.53 & 4.00 & 3.36 & 2.62 \\
\hline StDev & 2.55 & 2.05 & 1.75 & 1.66 & 1.72 & 1.81 & 2.01 & 1.73 & 1.61 & 1.61 & 1.68 & 1.76 \\
\hline \multicolumn{13}{|c|}{ 20-year PWRs } \\
\hline Mean & 9.01 & 8.50 & 7.96 & 7.36 & 6.81 & 6.23 & 9.55 & 8.93 & 8.30 & 7.67 & 7.05 & 6.44 \\
\hline Median & 8.78 & 8.60 & 7.91 & 7.21 & 6.38 & 5.30 & 9.75 & 8.91 & 8.02 & 7.25 & 6.57 & 5.90 \\
\hline Max & 15.06 & 12.72 & 12.68 & 12.61 & 12.46 & 12.22 & 14.27 & 13.11 & 12.68 & 12.62 & 12.51 & 12.35 \\
\hline Min & 4.28 & 4.44 & 4.48 & 4.35 & 4.19 & 3.82 & 5.81 & 5.65 & 5.43 & 5.04 & 4.54 & 3.80 \\
\hline StDev & 2.84 & 2.35 & 2.02 & 1.87 & 1.92 & 2.04 & 2.20 & 1.95 & 1.84 & 1.83 & 1.91 & 2.02 \\
\hline \multicolumn{13}{|c|}{ 10-year PWRs } \\
\hline Mean & 13.13 & 12.83 & 12.49 & 12.12 & 11.72 & 11.28 & 13.85 & 13.37 & 12.89 & 12.39 & 11.88 & 11.36 \\
\hline Median & 13.60 & 12.95 & 12.33 & 12.10 & 11.64 & 10.99 & 13.46 & 13.20 & 12.62 & 12.27 & 11.38 & 10.74 \\
\hline Max & 20.21 & 17.93 & 17.22 & 17.45 & 17.64 & 17.78 & 20.27 & 18.48 & 17.64 & 17.69 & 17.71 & 17.68 \\
\hline Min & 7.00 & 7.28 & 7.53 & 7.73 & 7.88 & 7.98 & 9.15 & 8.91 & 8.65 & 8.37 & 8.08 & 7.76 \\
\hline StDev & 3.31 & 2.74 & 2.31 & 2.08 & 2.07 & 2.24 & 2.57 & 2.32 & 2.16 & 2.11 & 2.14 & 2.25 \\
\hline \multicolumn{13}{|c|}{ 5-year PWRs } \\
\hline Mean & 22.66 & 22.43 & 22.17 & 21.88 & 21.56 & 21.20 & 23.28 & 22.90 & 22.50 & 22.09 & 21.66 & 21.22 \\
\hline Median & 22.86 & 22.58 & 22.25 & 22.02 & 21.67 & 21.21 & 22.84 & 22.74 & 22.46 & 22.09 & 21.57 & 21.10 \\
\hline Max & 31.56 & 30.16 & 28.67 & 27.27 & 27.54 & 27.95 & 31.76 & 29.45 & 28.05 & 27.22 & 27.45 & 27.66 \\
\hline Min & 13.53 & 14.83 & 15.67 & 16.51 & 16.50 & 15.34 & 16.27 & 16.92 & 17.00 & 16.93 & 16.70 & 15.93 \\
\hline StDev & 4.19 & 3.46 & 2.84 & 2.41 & 2.26 & 2.42 & 3.04 & 2.67 & 2.39 & 2.23 & 2.20 & 2.31 \\
\hline \multicolumn{13}{|c|}{ 3-year PWRs } \\
\hline Mean & 35.58 & 35.39 & 35.17 & 34.92 & 34.64 & 34.32 & 36.06 & 35.75 & 35.42 & 35.07 & 34.71 & 34.33 \\
\hline Median & 36.02 & 35.88 & 35.43 & 35.10 & 34.82 & 34.44 & 35.79 & 35.68 & 35.50 & 35.16 & 34.83 & 34.14 \\
\hline Max & 46.10 & 43.83 & 41.55 & 40.77 & 40.63 & 40.99 & 46.10 & 43.81 & 41.50 & 40.77 & 40.63 & 40.65 \\
\hline Min & 23.28 & 24.66 & 26.03 & 27.40 & 28.69 & 28.16 & 29.24 & 29.21 & 29.17 & 29.12 & 29.07 & 28.13 \\
\hline StDev & 4.87 & 4.02 & 3.27 & 2.68 & 2.38 & 2.46 & 3.34 & 2.87 & 2.49 & 2.24 & 2.18 & 2.30 \\
\hline \multicolumn{13}{|c|}{ 2-year PWRs } \\
\hline Mean & 51.64 & 51.51 & 51.35 & 51.17 & 50.96 & 50.72 & 52.00 & 51.78 & 51.54 & 51.28 & 51.01 & 50.72 \\
\hline Median & 52.70 & 52.22 & 51.72 & 51.39 & 51.28 & 50.82 & 51.98 & 51.96 & 51.60 & 51.18 & 50.85 & 50.59 \\
\hline Max & 60.51 & 59.08 & 57.55 & 56.22 & 57.02 & 57.86 & 59.87 & 58.25 & 56.60 & 56.63 & 57.25 & 57.86 \\
\hline Min & 37.78 & 40.77 & 42.43 & 43.76 & 45.06 & 45.82 & 45.87 & 46.08 & 46.28 & 46.47 & 46.17 & 45.34 \\
\hline StDev & 4.75 & 3.91 & 3.16 & 2.57 & 2.24 & 2.29 & 3.21 & 2.74 & 2.34 & 2.06 & 1.97 & 2.09 \\
\hline
\end{tabular}




\section{Table 5}

\begin{tabular}{|c|c|c|c|c|c|c|c|c|c|}
\hline \multicolumn{10}{|c|}{ Summary Statistics for Stock, Bond \& 60-40 Perfect Withdrawal Rates } \\
\hline \multirow{2}{*}{$\begin{array}{l}\text { PWR } \\
\text { Years }\end{array}$} & \multicolumn{3}{|c|}{$100 \%$ Stocks } & \multicolumn{3}{|c|}{$60-40$} & \multicolumn{3}{|c|}{$100 \%$ Bonds } \\
\hline & Max & Median & Min & Max & Median & Min & $\operatorname{Max}$ & Median & Min \\
\hline 30 & 12.81 & 7.50 & 3.69 & 10.85 & 5.97 & 3.57 & 9.92 & 3.17 & 2.42 \\
\hline 29 & 13.03 & 7.61 & 3.72 & 10.97 & 6.07 & 3.62 & 10.05 & 3.34 & 2.53 \\
\hline 28 & 13.23 & 7.67 & 3.75 & 11.12 & 6.15 & 3.66 & 10.20 & 3.48 & 2.63 \\
\hline 27 & 13.46 & 7.76 & 3.79 & 11.28 & 6.24 & 3.72 & 10.32 & 3.62 & 2.74 \\
\hline 26 & 13.78 & 7.88 & 3.84 & 11.41 & 6.36 & 3.78 & 10.48 & 3.79 & 2.85 \\
\hline 25 & 14.00 & 8.21 & 3.89 & 11.55 & 6.61 & 3.86 & 10.66 & 3.96 & 2.97 \\
\hline 24 & 14.17 & 8.36 & 3.95 & 11.71 & 6.85 & 3.93 & 10.83 & 4.14 & 3.10 \\
\hline 23 & 14.38 & 8.60 & 4.02 & 11.88 & 6.99 & 4.03 & 11.02 & 4.30 & 3.23 \\
\hline 22 & 14.62 & 9.03 & 4.10 & 12.06 & 7.14 & 4.13 & 11.23 & 4.58 & 3.38 \\
\hline 21 & 14.85 & 8.88 & 4.18 & 12.28 & 7.52 & 4.24 & 11.45 & 4.83 & 3.56 \\
\hline 20 & 15.06 & 8.78 & 4.28 & 12.48 & 7.86 & 4.39 & 11.70 & 5.10 & 3.75 \\
\hline 19 & 15.29 & 8.97 & 4.41 & 12.68 & 7.99 & 4.58 & 11.98 & 5.33 & 3.91 \\
\hline 18 & 15.57 & 9.26 & 4.53 & 12.88 & 8.20 & 4.80 & 12.32 & 5.64 & 4.13 \\
\hline 17 & 15.82 & 9.59 & 4.70 & 13.10 & 8.41 & 4.99 & 12.64 & 6.08 & 4.40 \\
\hline 16 & 16.12 & 9.87 & 4.92 & 13.38 & 8.73 & 5.25 & 13.01 & 6.44 & 4.70 \\
\hline 15 & 16.47 & 10.30 & 5.17 & 13.73 & 9.14 & 5.49 & 13.46 & 6.85 & 5.05 \\
\hline 14 & 16.97 & 10.84 & 5.44 & 14.14 & 9.64 & 5.70 & 13.93 & 7.41 & 5.47 \\
\hline 13 & 17.68 & 11.44 & 5.69 & 14.73 & 10.19 & 5.98 & 14.57 & 7.98 & 5.94 \\
\hline 12 & 18.36 & 12.14 & 6.05 & 15.33 & 10.78 & 6.39 & 15.21 & 8.67 & 6.46 \\
\hline 11 & 19.18 & 12.86 & 6.45 & 16.05 & 11.51 & 6.87 & 16.01 & 9.54 & 7.11 \\
\hline 10 & 20.21 & 13.60 & 7.00 & 17.23 & 12.34 & 7.50 & 16.95 & 10.76 & 7.83 \\
\hline 9 & 21.61 & 14.44 & 7.76 & 18.72 & 13.26 & 8.45 & 18.18 & 12.12 & 8.59 \\
\hline 8 & 23.10 & 15.61 & 8.60 & 20.72 & 14.72 & 9.55 & 19.60 & 13.51 & 9.55 \\
\hline 7 & 25.57 & 17.33 & 9.83 & 22.98 & 16.63 & 11.04 & 21.51 & 15.34 & 10.90 \\
\hline 6 & 28.15 & 19.65 & 11.47 & 25.55 & 18.77 & 13.02 & 23.95 & 17.64 & 12.63 \\
\hline 5 & 31.56 & 22.86 & 13.53 & 28.82 & 22.31 & 15.72 & 26.79 & 20.96 & 15.54 \\
\hline 4 & 37.71 & 27.98 & 16.43 & 33.32 & 27.45 & 19.31 & 31.98 & 25.93 & 20.29 \\
\hline 3 & 46.10 & 36.02 & 23.28 & 41.64 & 35.50 & 26.18 & 41.05 & 34.22 & 28.54 \\
\hline 2 & 60.51 & 52.70 & 37.78 & 56.97 & 51.74 & 43.16 & 57.48 & 50.52 & 45.31 \\
\hline
\end{tabular}




\begin{tabular}{|c|c|c|c|c|c|c|c|c|c|}
\hline \multicolumn{10}{|c|}{ Table 6} \\
\hline \multicolumn{10}{|c|}{ Summary Statistics for Stock, Bond \& 60-40 with Trend Following Perfect Withdrawal Rates } \\
\hline \multirow{2}{*}{$\begin{array}{l}\text { PWR } \\
\text { Years }\end{array}$} & \multicolumn{3}{|c|}{$100 \%$ Stocks TF } & \multicolumn{3}{|c|}{$60-40 \mathrm{TF}$} & \multicolumn{3}{|c|}{$100 \%$ Bonds TF } \\
\hline & Max & Median & Min & Max & Median & Min & Max & Median & Min \\
\hline 30 & 12.32 & 7.88 & 5.13 & 10.88 & 6.37 & 4.43 & 9.87 & 3.83 & 2.57 \\
\hline 29 & 12.46 & 7.97 & 5.19 & 11.00 & 6.48 & 4.49 & 10.06 & 3.94 & 2.66 \\
\hline 28 & 12.59 & 8.06 & 5.25 & 11.13 & 6.59 & 4.54 & 10.25 & 4.07 & 2.75 \\
\hline 27 & 12.75 & 8.09 & 5.31 & 11.27 & 6.71 & 4.61 & 10.41 & 4.23 & 2.84 \\
\hline 26 & 12.92 & 8.20 & 5.39 & 11.41 & 6.82 & 4.69 & 10.59 & 4.42 & 2.94 \\
\hline 25 & 13.10 & 8.41 & 5.46 & 11.57 & 6.98 & 4.76 & 10.78 & 4.57 & 3.05 \\
\hline 24 & 13.25 & 8.60 & 5.52 & 11.73 & 7.10 & 4.86 & 10.97 & 4.70 & 3.17 \\
\hline 23 & 13.43 & 8.89 & 5.58 & 11.89 & 7.26 & 4.96 & 11.17 & 4.94 & 3.30 \\
\hline 22 & 13.63 & 9.14 & 5.64 & 12.07 & 7.50 & 5.07 & 11.38 & 5.16 & 3.44 \\
\hline 21 & 13.91 & 9.51 & 5.73 & 12.26 & 7.77 & 5.19 & 11.58 & 5.38 & 3.60 \\
\hline 20 & 14.27 & 9.75 & 5.81 & 12.47 & 8.01 & 5.33 & 11.81 & 5.59 & 3.79 \\
\hline 19 & 14.59 & 9.85 & 5.90 & 12.69 & 8.17 & 5.47 & 12.05 & 5.87 & 4.01 \\
\hline 18 & 15.00 & 9.96 & 6.02 & 12.91 & 8.29 & 5.64 & 12.34 & 6.17 & 4.25 \\
\hline 17 & 15.46 & 10.30 & 6.22 & 13.17 & 8.65 & 5.89 & 12.63 & 6.48 & 4.53 \\
\hline 16 & 15.98 & 10.62 & 6.42 & 13.46 & 8.96 & 6.17 & 12.98 & 6.84 & 4.84 \\
\hline 15 & 16.49 & 10.86 & 6.66 & 13.91 & 9.34 & 6.49 & 13.38 & 7.25 & 5.15 \\
\hline 14 & 17.05 & 11.29 & 6.98 & 14.49 & 9.78 & 6.85 & 13.80 & 7.73 & 5.54 \\
\hline 13 & 17.74 & 11.65 & 7.40 & 15.11 & 10.33 & 7.20 & 14.37 & 8.17 & 5.98 \\
\hline 12 & 18.43 & 12.08 & 7.93 & 15.72 & 10.98 & 7.66 & 14.99 & 8.82 & 6.50 \\
\hline 11 & 19.24 & 12.68 & 8.47 & 16.45 & 11.75 & 8.21 & 15.77 & 9.53 & 7.11 \\
\hline 10 & 20.27 & 13.46 & 9.15 & 17.25 & 12.60 & 8.89 & 16.68 & 10.46 & 7.82 \\
\hline 9 & 21.66 & 14.52 & 9.91 & 18.50 & 13.59 & 9.94 & 17.88 & 11.60 & 8.67 \\
\hline 8 & 23.19 & 15.92 & 10.98 & 20.20 & 14.82 & 11.25 & 19.25 & 13.03 & 9.83 \\
\hline 7 & 25.53 & 17.41 & 12.11 & 22.28 & 16.66 & 12.53 & 21.09 & 14.84 & 11.40 \\
\hline 6 & 28.19 & 19.67 & 13.79 & 24.89 & 19.24 & 14.29 & 23.44 & 17.35 & 13.22 \\
\hline 5 & 31.76 & 22.84 & 16.27 & 28.30 & 22.30 & 16.85 & 26.72 & 20.74 & 16.36 \\
\hline 4 & 37.67 & 27.79 & 20.80 & 33.06 & 27.18 & 21.00 & 32.20 & 25.72 & 20.60 \\
\hline 3 & 46.10 & 35.79 & 29.24 & 41.63 & 35.31 & 28.96 & 41.05 & 34.01 & 28.47 \\
\hline 2 & 59.87 & 51.98 & 45.87 & 56.76 & 51.35 & 46.43 & 57.48 & 50.31 & 44.08 \\
\hline
\end{tabular}




\begin{tabular}{|c|c|c|c|c|c|c|c|c|c|c|}
\hline \multicolumn{11}{|c|}{ Table 7} \\
\hline \multicolumn{11}{|c|}{$\begin{array}{c}\text { Perfect Withdrawal Rates Based on Optimal Asset Allocation using Percentiles from Monte } \\
\text { Carlo Simulations With and Without Trend Following }\end{array}$} \\
\hline & \multicolumn{5}{|c|}{ Standard } & \multicolumn{5}{|c|}{ Trend Following } \\
\hline & $1 \mathrm{st}$ & 5th & 10th & 25th & 50th & 1st & 5 th & 10th & 25 th & 50th \\
\hline 30 & 3.01 & 3.72 & 4.18 & 5.25 & 7.20 & 4.17 & 5.08 & 5.68 & 6.83 & 8.31 \\
\hline 29 & 3.08 & 3.80 & 4.28 & 5.34 & 7.29 & 4.22 & 5.16 & 5.76 & 6.89 & 8.37 \\
\hline 28 & 3.15 & 3.90 & 4.36 & 5.45 & 7.39 & 4.29 & 5.22 & 5.83 & 6.97 & 8.44 \\
\hline 27 & 3.26 & 3.99 & 4.46 & 5.53 & 7.51 & 4.38 & 5.32 & 5.91 & 7.04 & 8.53 \\
\hline 26 & 3.36 & 4.09 & 4.57 & 5.64 & 7.60 & 4.46 & 5.41 & 6.01 & 7.16 & 8.64 \\
\hline 25 & 3.46 & 4.20 & 4.68 & 5.75 & 7.73 & 4.56 & 5.51 & 6.11 & 7.25 & 8.74 \\
\hline 24 & 3.59 & 4.33 & 4.82 & 5.89 & 7.85 & 4.67 & 5.59 & 6.21 & 7.37 & 8.85 \\
\hline 23 & 3.72 & 4.46 & 4.95 & 6.04 & 8.02 & 4.82 & 5.73 & 6.33 & 7.49 & 9.00 \\
\hline 22 & 3.86 & 4.64 & 5.12 & 6.19 & 8.20 & 4.94 & 5.86 & 6.47 & 7.64 & 9.14 \\
\hline 21 & 4.03 & 4.79 & 5.28 & 6.38 & 8.38 & 5.08 & 6.01 & 6.62 & 7.81 & 9.30 \\
\hline 20 & 4.20 & 4.99 & 5.48 & 6.57 & 8.59 & 5.27 & 6.18 & 6.80 & 7.98 & 9.49 \\
\hline 19 & 4.39 & 5.19 & 5.69 & 6.80 & 8.82 & 5.45 & 6.36 & 6.98 & 8.17 & 9.71 \\
\hline 18 & 4.61 & 5.42 & 5.94 & 7.04 & 9.09 & 5.64 & 6.60 & 7.22 & 8.40 & 9.94 \\
\hline 17 & 4.86 & 5.70 & 6.20 & 7.32 & 9.38 & 5.91 & 6.83 & 7.45 & 8.66 & 10.23 \\
\hline 16 & 5.16 & 6.00 & 6.52 & 7.63 & 9.71 & 6.18 & 7.11 & 7.73 & 8.96 & 10.53 \\
\hline 15 & 5.48 & 6.33 & 6.86 & 7.99 & 10.09 & 6.52 & 7.44 & 8.06 & 9.30 & 10.87 \\
\hline 14 & 5.85 & 6.72 & 7.26 & 8.40 & 10.54 & 6.87 & 7.81 & 8.44 & 9.68 & 11.27 \\
\hline 13 & 6.30 & 7.20 & 7.75 & 8.89 & 11.07 & 7.32 & 8.26 & 8.89 & 10.15 & 11.77 \\
\hline 12 & 6.82 & 7.73 & 8.29 & 9.47 & 11.67 & 7.85 & 8.79 & 9.41 & 10.68 & 12.32 \\
\hline 11 & 7.45 & 8.39 & 8.96 & 10.16 & 12.39 & 8.45 & 9.41 & 10.05 & 11.34 & 13.00 \\
\hline 10 & 8.19 & 9.17 & 9.77 & 10.98 & 13.26 & 9.22 & 10.19 & 10.82 & 12.14 & 13.84 \\
\hline 9 & 9.16 & 10.15 & 10.77 & 12.00 & 14.34 & 10.17 & 11.15 & 11.78 & 13.12 & 14.84 \\
\hline 8 & 10.34 & 11.38 & 12.00 & 13.29 & 15.66 & 11.36 & 12.37 & 13.00 & 14.34 & 16.14 \\
\hline 7 & 11.88 & 12.98 & 13.65 & 14.95 & 17.42 & 12.92 & 13.97 & 14.61 & 15.97 & 17.82 \\
\hline 6 & 13.99 & 15.14 & 15.82 & 17.20 & 19.74 & 15.03 & 16.12 & 16.76 & 18.12 & 20.04 \\
\hline 5 & 16.98 & 18.20 & 18.92 & 20.36 & 23.04 & 18.02 & 19.17 & 19.85 & 21.19 & 23.19 \\
\hline 4 & 21.63 & 22.86 & 23.63 & 25.16 & 27.94 & 22.63 & 23.83 & 24.54 & 25.85 & 27.92 \\
\hline 3 & 29.64 & 30.77 & 31.62 & 33.23 & 36.05 & 30.50 & 31.70 & 32.49 & 33.81 & 35.90 \\
\hline 2 & 45.82 & 47.34 & 48.00 & 49.74 & 52.63 & 46.57 & 47.81 & 48.98 & 50.17 & 51.96 \\
\hline
\end{tabular}


Figure 1.

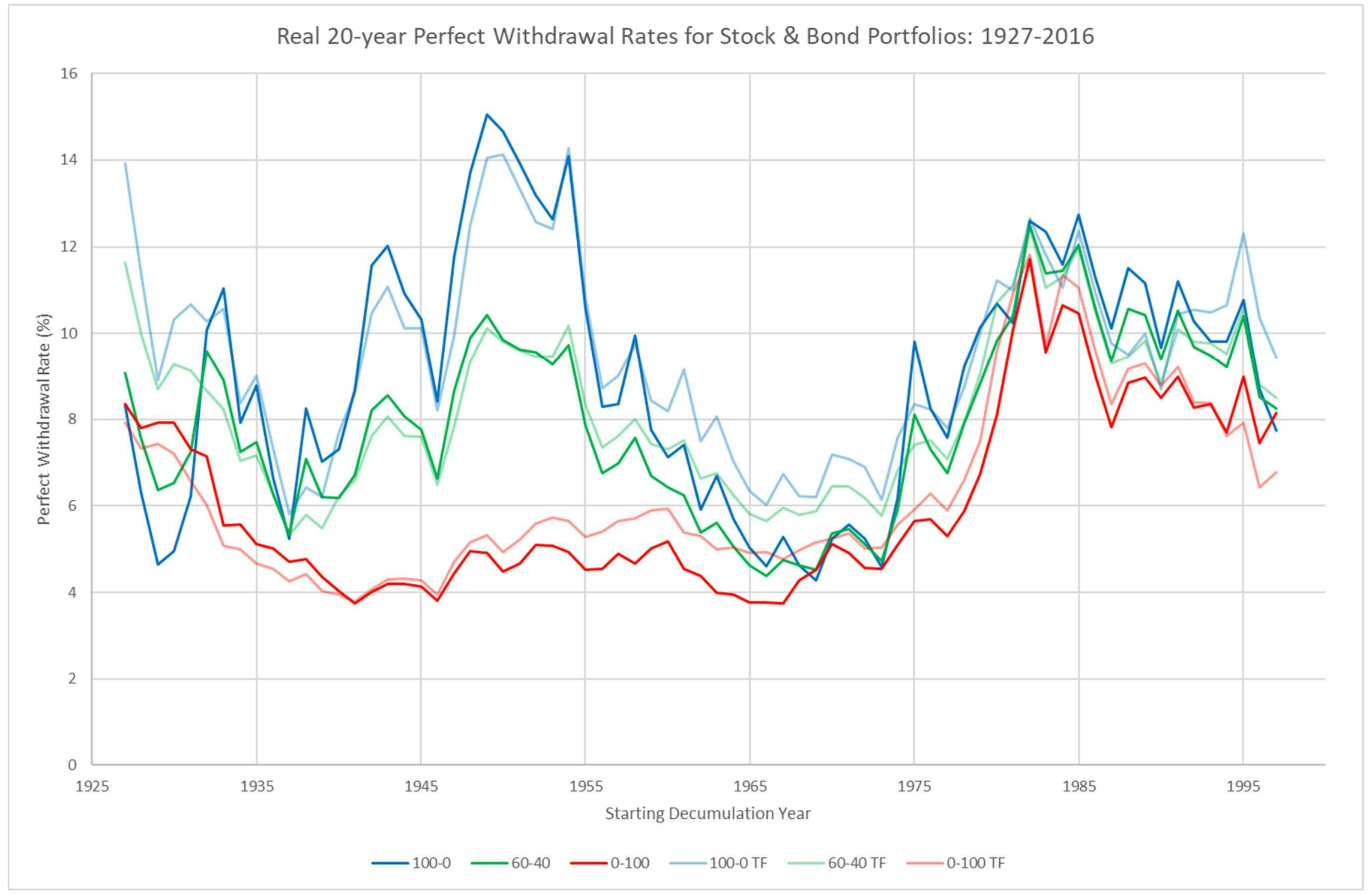


Figure 2.

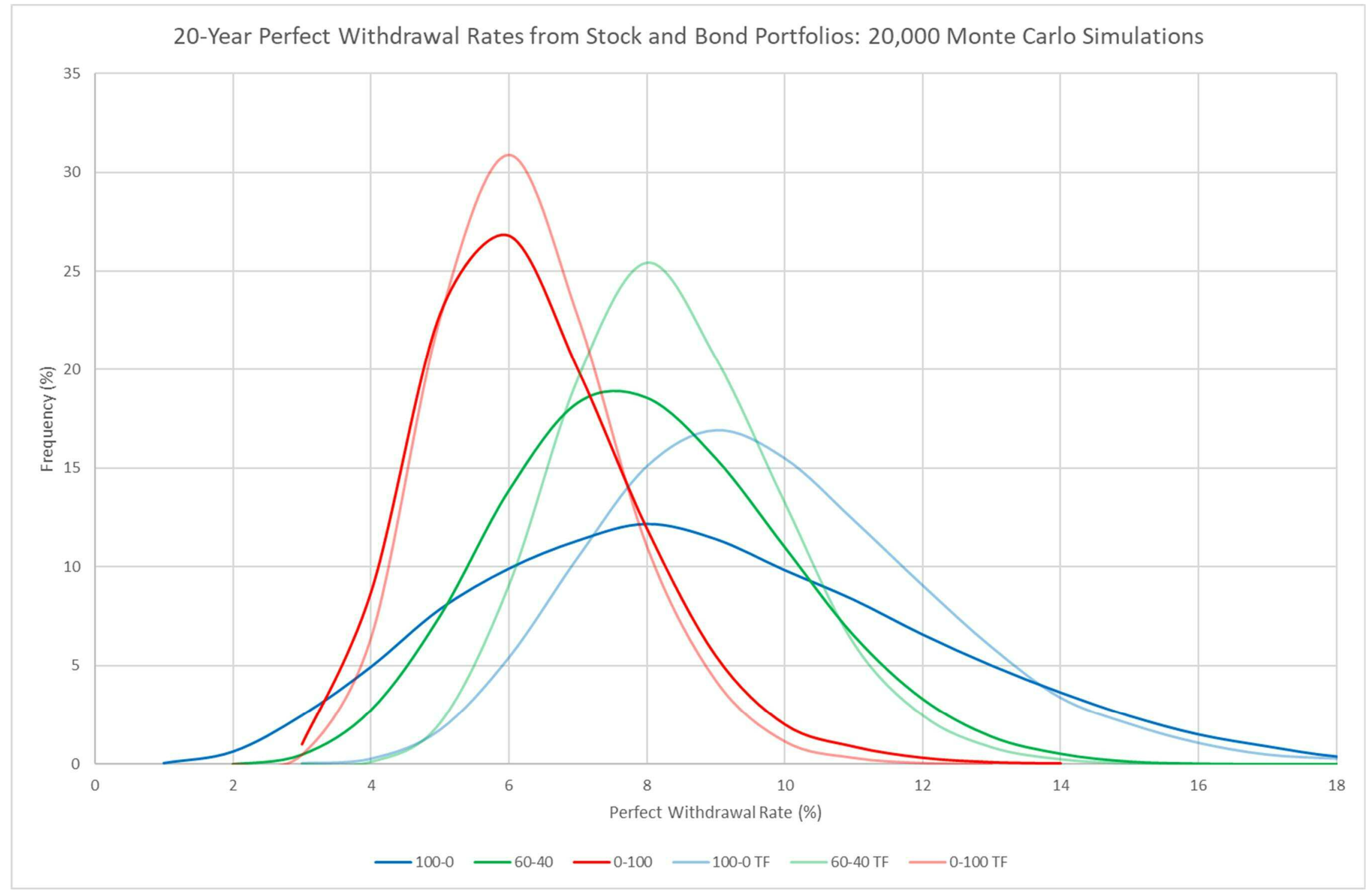


Figure 3.

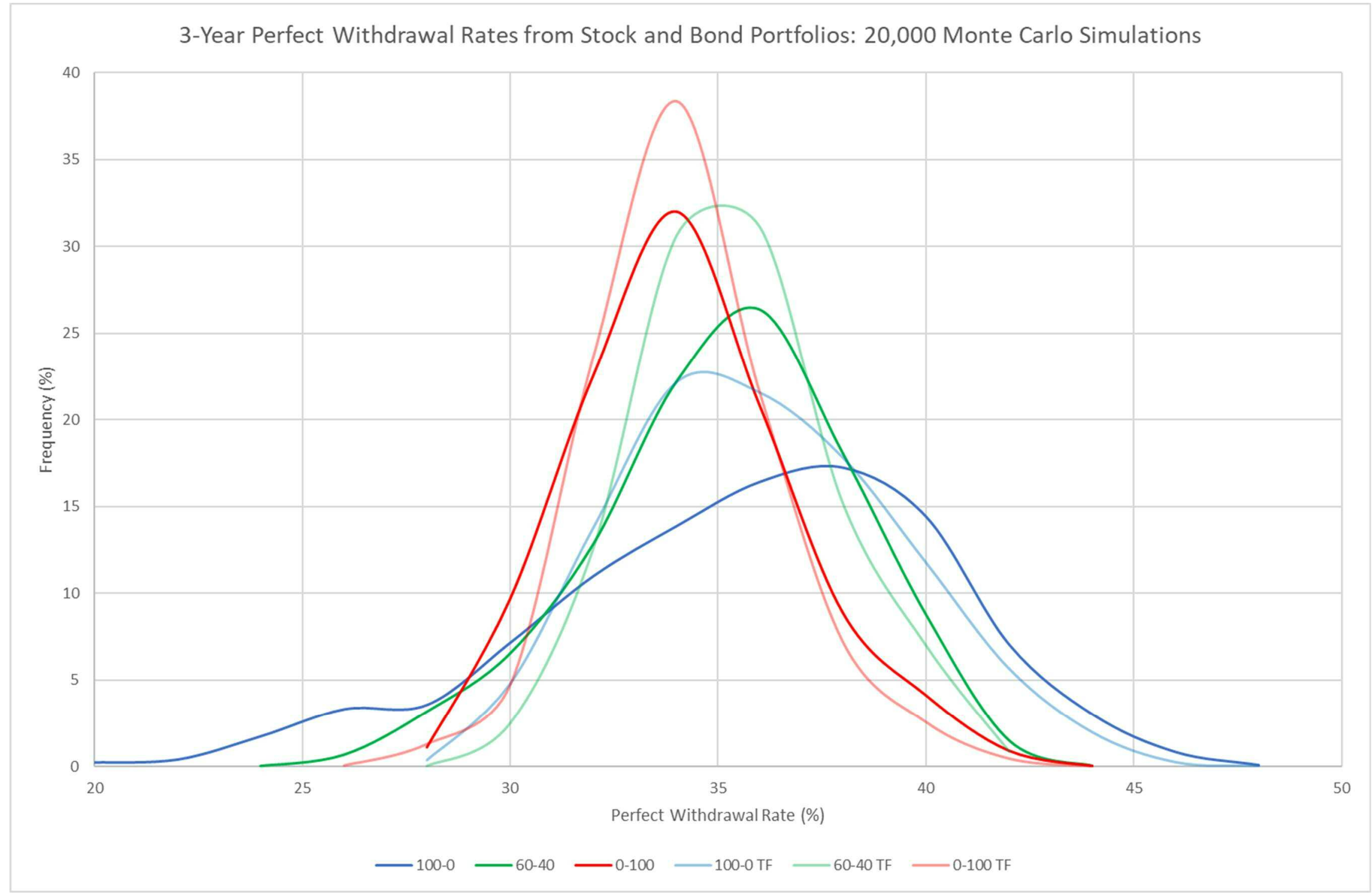


Figure 4.

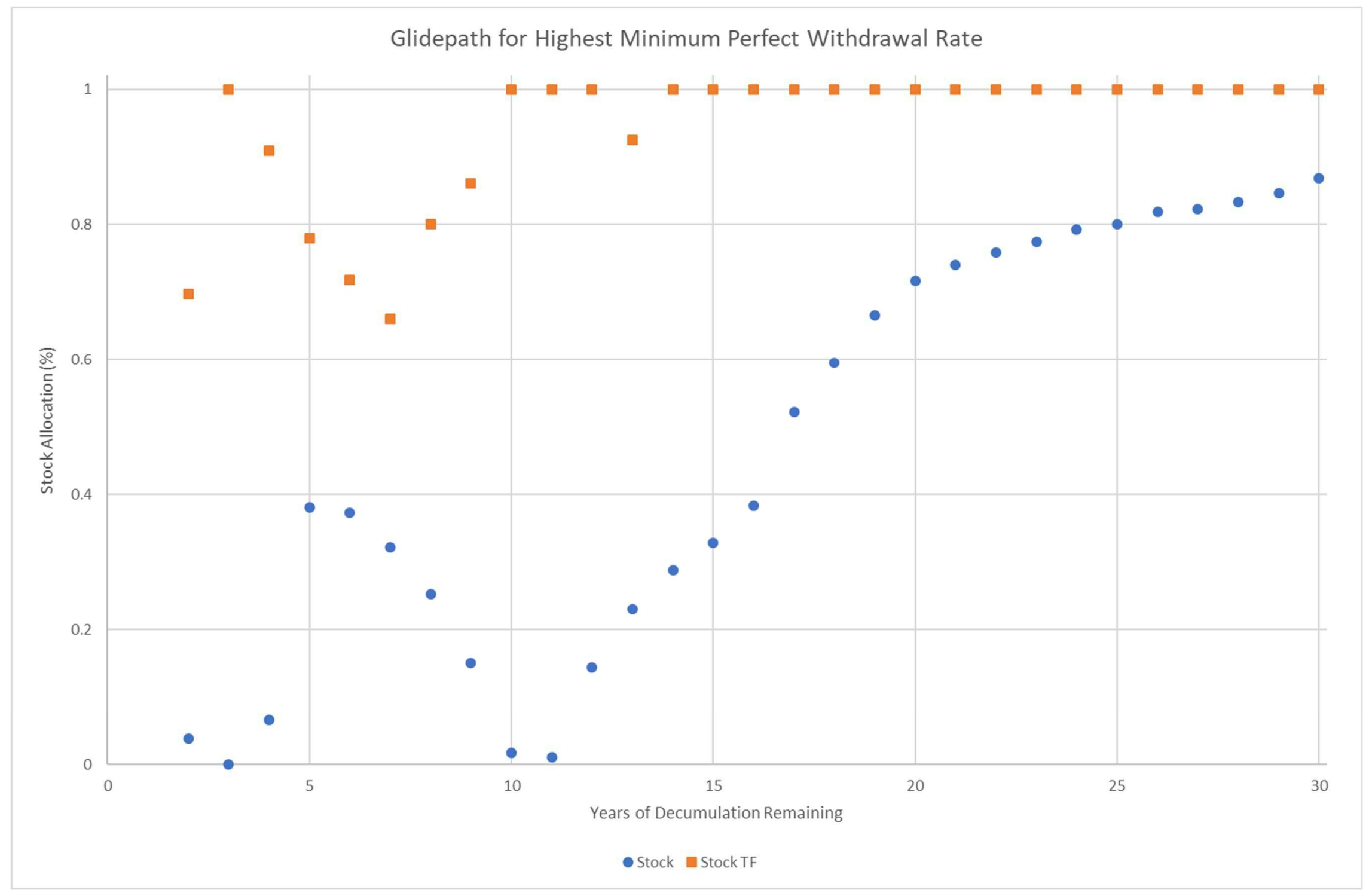


Figure 5.

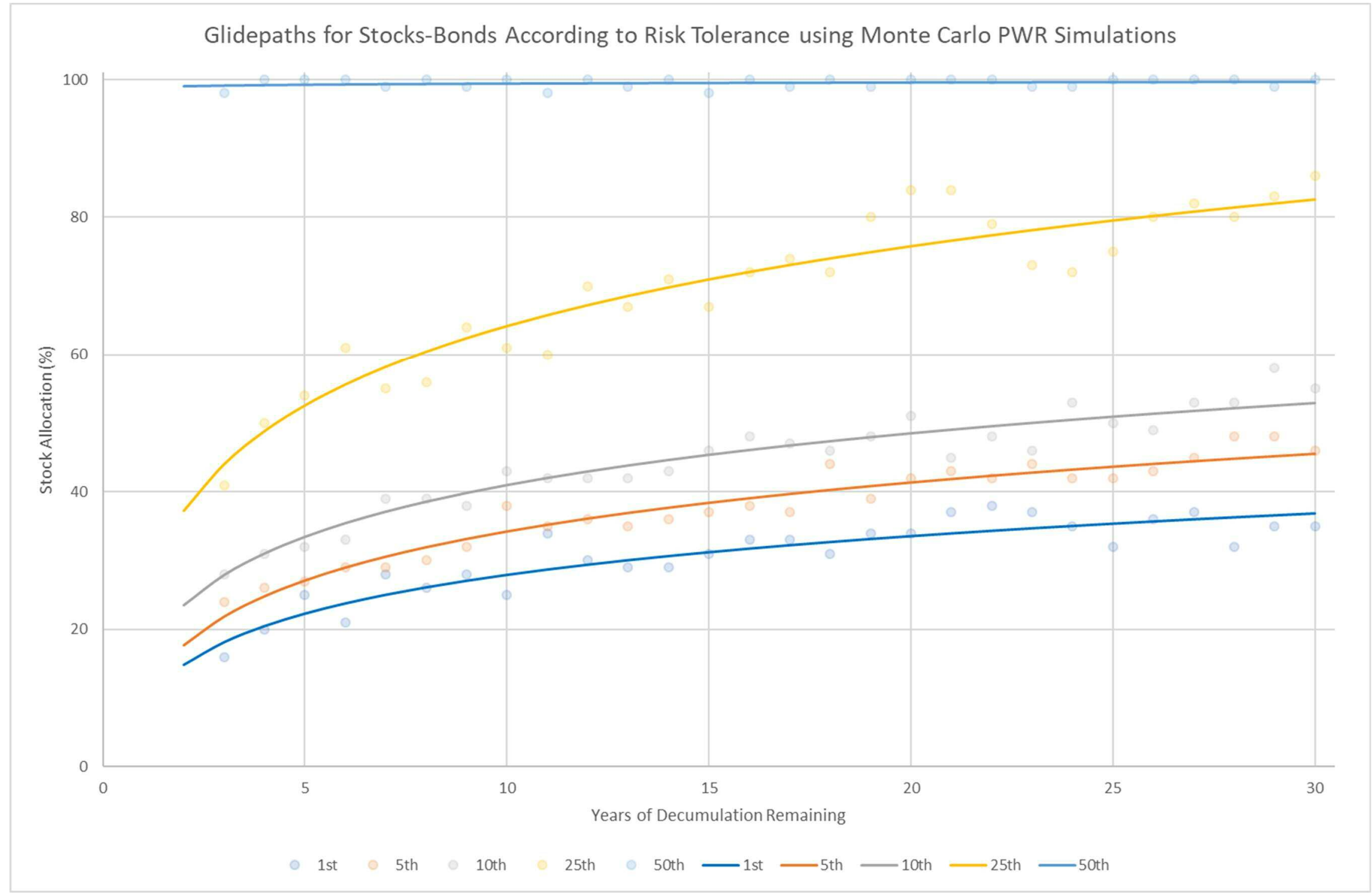


Figure 6.

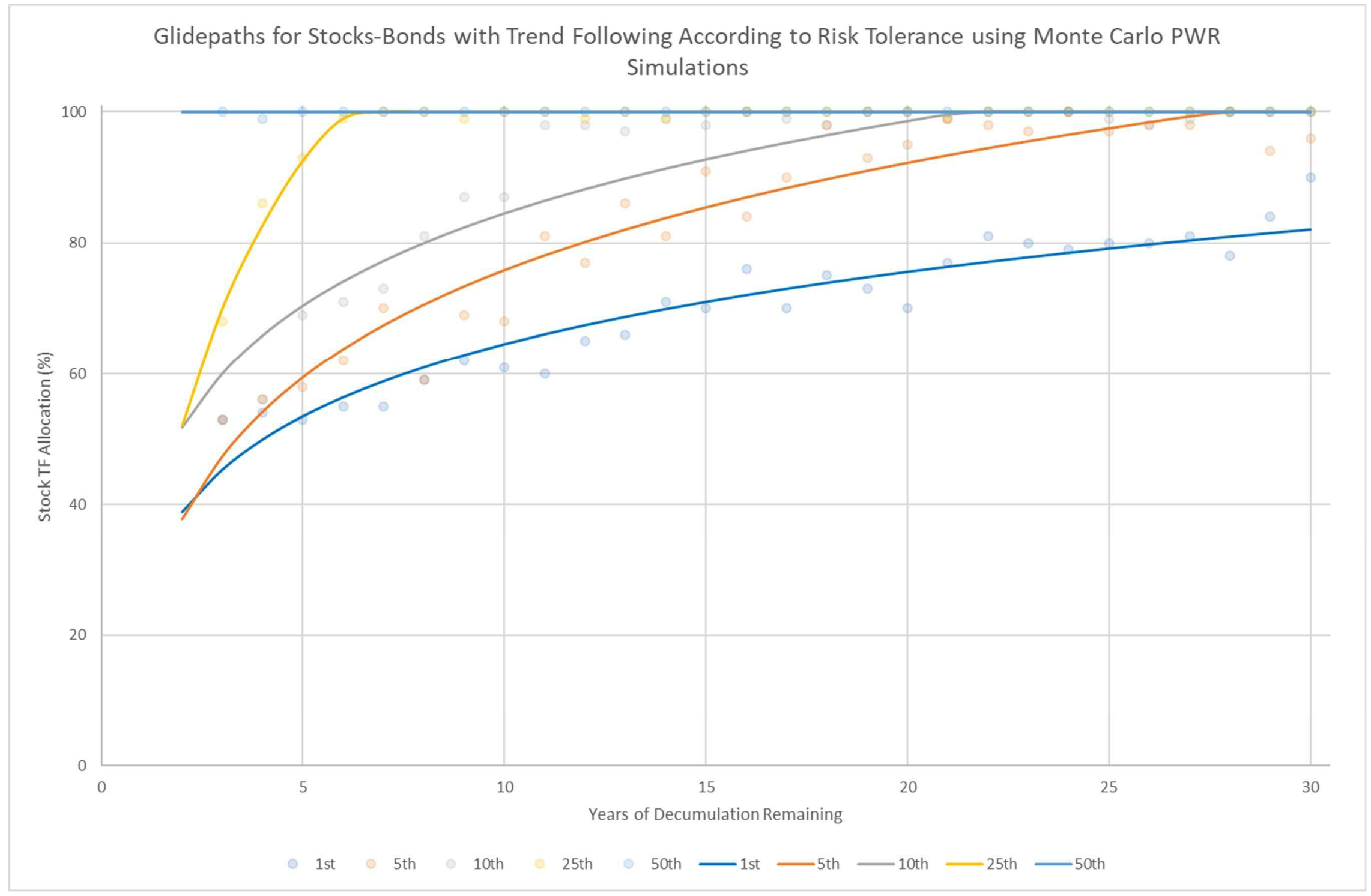

